\title{
Review Article \\ Snake Venom L-Amino Acid Oxidases: Trends in Pharmacology and Biochemistry
}

\author{
Luiz Fernando M. Izidoro, ${ }^{1}$ Juliana C. Sobrinho, ${ }^{2}$ Mirian M. Mendes, ${ }^{1}$ \\ Tássia R. Costa, ${ }^{3}$ Amy N. Grabner, ${ }^{2}$ Veridiana M. Rodrigues, ${ }^{1}$ Saulo L. da Silva, ${ }^{4}$ \\ Fernando B. Zanchi, ${ }^{2}$ Juliana P. Zuliani, ${ }^{2}$ Carla F. C. Fernandes, ${ }^{2}$ \\ Leonardo A. Calderon, ${ }^{2}$ Rodrigo G. Stábeli, ${ }^{2}$ and Andreimar M. Soares ${ }^{2}$ \\ ${ }^{1}$ Faculdade de Ciências Integradas do Pontal e Departamento de Genética e Bioquímica, \\ Universidade Federal de Uberlândia (UFU), Uberlândia, MG, Brazil \\ ${ }^{2}$ Centro de Estudos de Biomoléculas Aplicadas à Saúde, (CEBio), Fundação Oswaldo Cruz, \\ Fiocruz Rondônia e Departamento de Medicina, Universidade Federal de Rondônia (UNIR), Porto Velho, RO, Brazil \\ ${ }^{3}$ Departamento de Análises Clínicas, Toxicológicas e Bromatológicas, \\ Faculdade de Ciências Farmacêuticas de Ribeirão Preto (FCFRP), Universidade de São Paulo (USP), Ribeirão Preto, SP, Brazil \\ ${ }^{4}$ Departamento de Química, Biotecnologia e Engenharia de Bioprocessos, Universidade Federal de São João del Rei (UFSJ), \\ Campus Altoparaopeba, Ouro Branco, MG, Brazil
}

Correspondence should be addressed to Andreimar M. Soares; andreimar@fiocruz.br

Received 20 October 2013; Revised 13 December 2013; Accepted 16 December 2013; Published 12 March 2014

Academic Editor: Fernando Albericio

Copyright (C) 2014 Luiz Fernando M. Izidoro et al. This is an open access article distributed under the Creative Commons Attribution License, which permits unrestricted use, distribution, and reproduction in any medium, provided the original work is properly cited.

\begin{abstract}
L-amino acid oxidases are enzymes found in several organisms, including venoms of snakes, where they contribute to the toxicity of ophidian envenomation. Their toxicity is primarily due to enzymatic activity, but other mechanisms have been proposed recently which require further investigation. L-amino acid oxidases exert biological and pharmacological effects, including actions on platelet aggregation and the induction of apoptosis, hemorrhage, and cytotoxicity. These proteins present a high biotechnological potential for the development of antimicrobial, antitumor, and antiprotozoan agents. This review provides an overview of the biochemical properties and pharmacological effects of snake venom L-amino acid oxidases, their structure/activity relationship, and supposed mechanisms of action described so far.
\end{abstract}

\section{Composition of Snake Venoms}

During the continuing evolution of snakes, according to Kardong [1], the development of more specialized glandular venom was essential in the emergence of biologically active substances capable of weakening prey to facilitate their capture. At first the discharge's main function was to lubricate the snake's food, but with the passage of time, some enzymes mixed with secretions allowing for the emergence of more elaborate and potentially toxic proteins, used in the immobilization of prey. A quantitative increase in the production of these secretions as well as a qualitative improvement of toxic proteins promoted a gain in absolute discretion in defense against predators [2]. Qualitatively, snake venoms consist of a mixture of protein with or without catalytic activity such as phospholipases $\mathrm{A}_{2}\left(\mathrm{PLA}_{2}\right)$, proteases, hyaluronidases, L-amino acid oxidases (LAAOs), acetylcholinesterases, growth factors, protein $\mathrm{C}$ activators, lectins, and von Willebrand factor-binding proteins; peptides mainly comprising bradykinin potentiators and disintegrins; low molecular weight organic compounds such as carbohydrates, serotonin, histamine, citrate, and nucleosides; and inorganic ions such as calcium, cobalt, magnesium, copper, iron, and potassium, as well as enzymatic inhibitors [3]. 


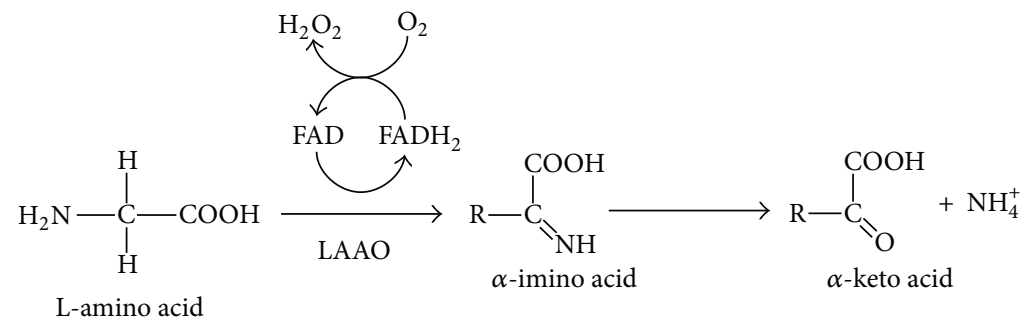

FIGURE 1: Mechanism of chemical reaction catalyzed by L-amino acid oxidases (LAAOs) [37].

\section{L-Amino Acid Oxidases}

LAAOs are widely distributed in many different species including insects, fungi, bacteria, and snakes [4] and are even found in plants where one of their catalytic products, ammonia, is used as a nitrogen source in cell metabolism $[5,6]$.

LAAO activity was first observed by Krebs [7] in hepatic and renal tissue homogenates. Subsequently, Blanchard et al. [8] isolated the first LAAO from a rat kidney. Regarding snake venoms, this class of molecules was only detected in 1944 by Zeller and Maritiz [9] who studied the venom of Vipera aspis. In 1979, Iwanaga and Suzuki [10] described the potential of LAAOs as enzymes when observing a highly specific chemical reaction with L-amino acids. Snake venom LAAOs (SVLAAOs) are usually homodimeric with cofactors FAD (Flavin Adenine Dinucleotide) or FMN (Flavin Mononucleotide) covalently linked to their chemical structure. The yellow color of venoms rich in these enzymes is related to the presence of the pigment riboflavin present in the cofactors, a fact that facilitates its purification. Quantitatively, there are inter- and intraspecific variations in the content of this enzyme in the whole venom (Table 1), and therefore there is color variance between the venoms. In exceptional cases, one gland of the same individual may produce yellow venom and the other gland colorless venom as observed in Crotalus viridis helleri [11].

In snake venoms, LAAOs are found in high concentrations that vary according to each species of snakse, which may contribute to the toxicity of the venom. LAAOs exhibit catalytic specificity for long chain hydrophobic and aromatic amino acids and are active in a wide range of $\mathrm{pHs}$ and temperatures. Their structures, molecular masses, and isoelectric points are quite varied. They are able to induce changes in platelet function, which cause local effects on plasma clotting disorders among other things. LAAOs are capable of inducing apoptosis in various cell lines and show antimicrobial and antiparasitic activity. According to Ande et al. [36] the existence of LAAOs may be a means of protection against natural agents, parasites, and bacteria.

\section{Enzymatic Activity of L-Amino Acid Oxidases}

LAAOs (EC 1.4.3.2) are flavoenzymes belonging to the class of oxidoreductases that catalyze the stereospecific oxidative deamination of L-amino acids. During the reduction halfreaction, the amino acid substrate is oxidized to an imino acid, with a concomitant reduction of the FAD cofactor. The imino acid then undergoes nonenzymatic hydrolysis, yielding $\alpha$-keto acid and ammonia. Another oxidation halfreaction completes the catalytic cycle, reoxidizing $\mathrm{FADH}_{2}$ in the presence of molecular oxygen and thus generating hydrogen peroxide (Figure 1).

LAAOs are considered to be a class of multifunctional enzymes in view of their ability to produce hydrogen peroxide and ammonia, their participation in cell metabolism, and their possible protective effects, including their antiseptic and antimicrobial activities on different organisms. Furthermore, the correlation between the production of LAAOs and their utilization in metabolic pathways involving nitrogen, as well as the production of hydrogen peroxide, opens perspectives for new applications of these enzymes as bactericidal, antiviral, and antitumor agents, making them a promising biotechnological agent. Thus various research groups have studied LAAOs isolated from different snake species $[12,14$, $15,20,21,23,24,29,30,32-35,38-48]$.

3.1. Importance of Hydrogen Peroxide. The hydrogen peroxide generated during the enzymatic reaction is a highly toxic oxygen reactive species that is capable of acting on nucleic acids, proteins, and plasma cell membranes [49]. This reactive oxygen species, according to Ande et al. [36], is formed extracellularly, may act directly on cell membranes by altering the permeability of the attacked area, and may also be involved in necrosis or apoptosis. The process of necrosis could be related to the direct action of hydrogen peroxide on the plasma cell membrane, since within the mechanism of apoptosis the development of morphological, biochemical, and molecular changes leads to cell death. The most common morphological changes were chromatin condensation, reduction and disintegration of nucleolus volume, and others. It also seems to be involved in the cytotoxic mechanisms of the enzyme which may ultimately represent another defense mechanism of the organism in response to the environment.

3.2. Enzymatic Kinetics of L-Amino Acid Oxidases. Kinetic studies suggest that LAAOs present preferential catalytic specificity for hydrophobic and aromatic L-amino acids (Table 1), whereas their affinity for polar and basic amino acids is low $[12,15,16,21,24,28,30,32,33,35,44,46,47]$. 


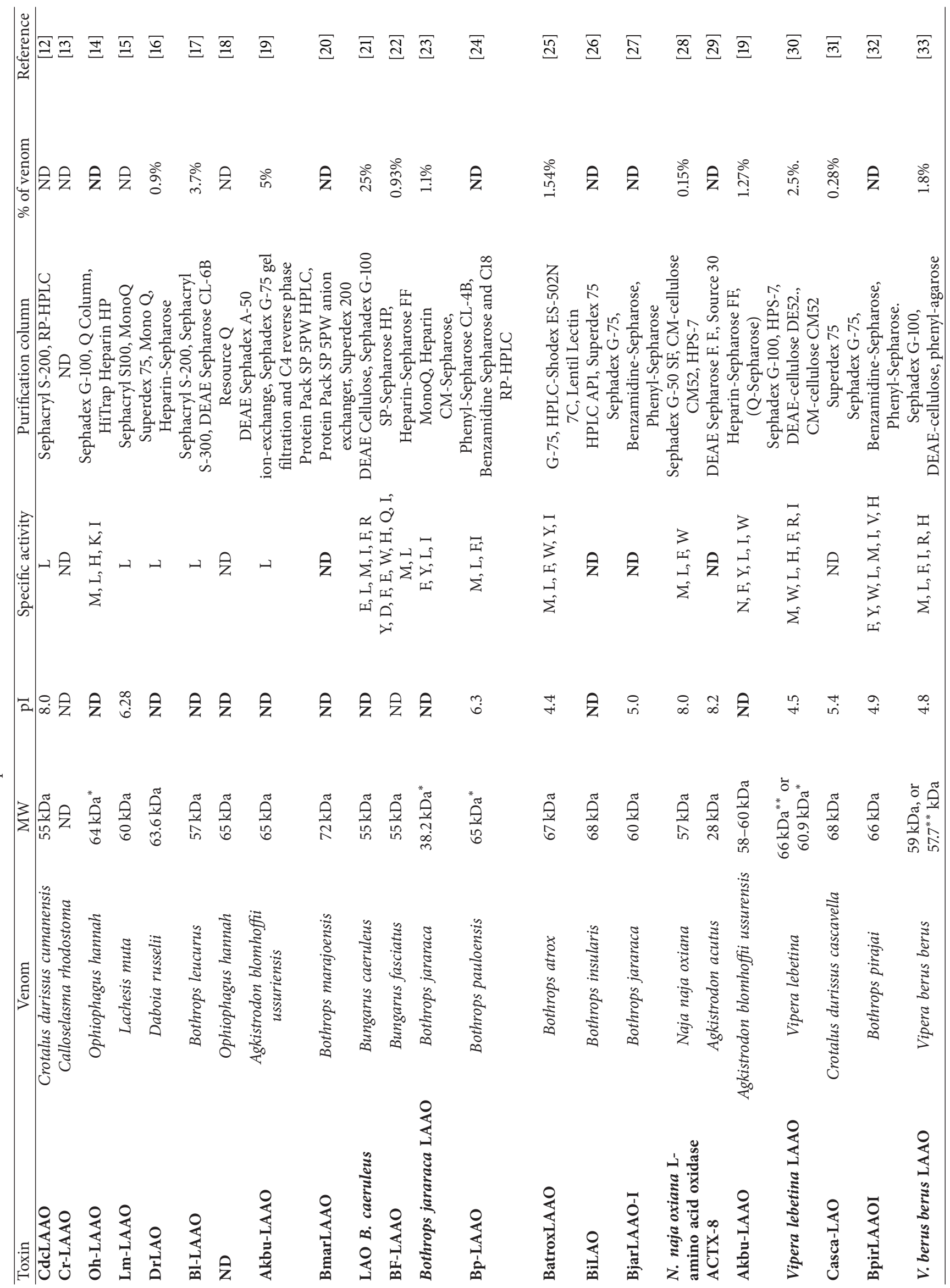




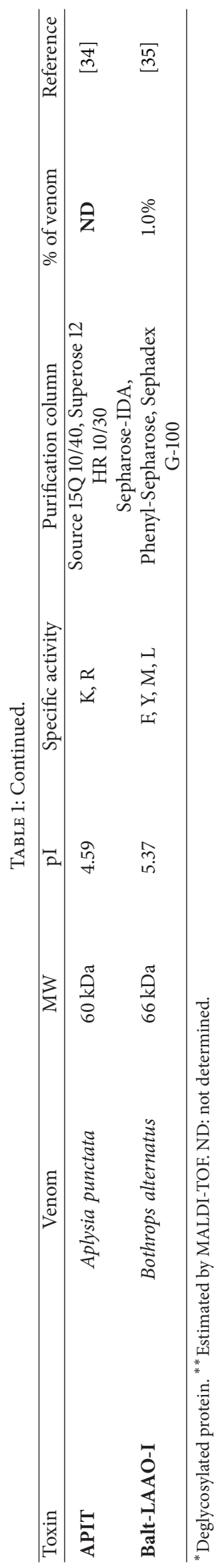


TABLE 2: Kinetic parameters of L-amino acid oxidase from snake venom on specific substrates.

\begin{tabular}{|c|c|c|c|c|c|c|c|c|c|}
\hline \multirow{2}{*}{ Snake } & \multicolumn{2}{|c|}{ Leu } & \multicolumn{2}{|c|}{ Met } & \multicolumn{2}{|c|}{ Trp } & \multicolumn{2}{|c|}{ Phe } & \multirow{2}{*}{ Reference } \\
\hline & $K_{m}(\mathrm{mM})$ & $K_{\text {cat }}\left(\mathrm{s}^{-1}\right)$ & $K_{m}(\mathrm{mM})$ & $K_{\text {cat }}\left(\mathrm{s}^{-1}\right)$ & $K_{m}(\mathrm{mM})$ & $K_{\text {cat }}\left(\mathrm{s}^{-1}\right)$ & $K_{m}(\mathrm{mM})$ & $K_{\text {cat }}\left(\mathrm{s}^{-1}\right)$ & \\
\hline Crotalus durissus cumanensis & 9.23 & 1.8 & ND & ND & ND & ND & ND & ND & {$[12]$} \\
\hline Daboia russelii & 490 & 2.153 & 373 & 2.193 & 81 & 4.056 & 142 & 4.130 & {$[16]$} \\
\hline Lachesis muta & 0.97 & ND & ND & ND & ND & ND & ND & ND & [15] \\
\hline Bungarus fasciatus & 60.69 & 1025.05 & 15.03 & 589.33 & 0.27 & 98.82 & 84.08 & 142.62 & [55] \\
\hline Naja naja oxiana & 0.75 & 47.98 & 0.885 & 66.26 & 0.147 & 18.04 & 0.051 & 17.18 & [28] \\
\hline Agkistrodon blomhoffii ussurensis & 0.11 & 48.22 & 0.88 & 24.13 & 0.023 & 6.58 & 0.042 & 48.23 & [19] \\
\hline Vipera berus berus & 0.361 & 75.16 & 0.286 & 74.20 & - & - & 0.058 & 28.50 & [33] \\
\hline Vipera lebetina & 0.40 & 52.0 & 0.65 & 80.3 & 0.17 & 42.65 & - & - & {$[30]$} \\
\hline Naja naja kaouthia & 0.66 & 23.4 & 0.63 & 24.4 & 0.29 & 12.47 & 0.06 & 10.75 & {$[56]$} \\
\hline Calloselasma rhodostoma & 0.63 & 3.30 & 0.24 & 1.65 & 0.08 & 0.88 & 0.05 & 0.72 & {$[53]$} \\
\hline Ophiophagus hannah & 0.20 & 96.2 & 0.63 & 65.6 & 0.10 & 32.1 & 0.10 & 54.1 & {$[57]$} \\
\hline
\end{tabular}

ND: not determined.

Positively charged amino acids such as L-lysine and L-arginine present unfavorable electrostatic interactions with the catalytic site of the enzyme [50].

Oxidation catalyzed by LAAOs follows Michaelis-Menten kinetics $[6,14,15,28,29,31,33,34,46,48,49,51-54]$. The kinetic parameters $K_{m}$ and $K_{\text {cat }}$ shown in Table 2 are very useful for the study and comparison of different enzymes in relation to their substrate. Each enzyme presents optimal $K_{m}$ and $K_{\text {cat }}$ values that reflect the cellular environment, substrate concentration, and chemical characteristics of the reaction catalyzed. $K_{m}$, the Michaelis-Menten constant, often used as an indicator of the affinity of the enzyme for the substrate, is specific for each L-amino acid oxidized by LAAOs [29], whereas $K_{\text {cat }}$ is the number of substrate molecules converted into the product per unit of time. The maximum velocity $\left(V_{\max }\right)$ reached in each enzymatic reaction is associated with the concentration of the substrate present in the medium and with $K_{m}$ and is also specific for each substrate $[12,15,16,21$, $31,48,49,54]$.

3.2.1. Effect of $p H$ on the Enzymatic Kinetics of L-Amino Acid Oxidases. The oxidation of L-amino acids by LAAOs happens in a wide range of $\mathrm{pHs}$. This maximal specific activity of each LAAO is related to the optimum $\mathrm{pH}$ for each type of amino acid acting as the substrate [58]. Paik and Kim [51] extensively studied the relationship between $\mathrm{pH}$ and substrate reactivity for LAAOs from snake venom and found different $\mathrm{pH}$ curves depending on the amino acid used as the substrate. Solis et al. [59] studied the action of LAAOs isolated from the venom of Bothrops brazili on the substrates Lleucine, L-methionine, L-phenylalanine, and L-arginine and observed that the enzyme remained active in a wide range of $\mathrm{pH}$ values; however the activity was highest at a $\mathrm{pH}$ of 8.5. Other amino acids such as L-isoleucine, L-tryptophan, and Llysine showed optimum pHs of 7.5, 8.0 and 9.0, respectively; indeed various LAAOs also catalyze specific oxidoreduction reactions within a broad range of medium pHs $[6,15,21,29$, $31,34,44,47,53]$. The different profiles of specificity in terms of substrate and $\mathrm{pH}$ are related to the acid-base behavior of the enzyme in response to the amino acid. At a certain $\mathrm{pH}$, both the enzyme and the substrate are in ionic equilibrium, permitting a better fit of the substrate in the active site of the enzyme and consequent maximum oxidation.

Snake venom LAAOs can suffer two types of reversible inactivation. One factor inducing inactivation is a change in $\mathrm{pH}$ to values close to neutral, resulting in a spontaneous structural change of the enzyme to its inactive configuration. If the $\mathrm{pH}$ is lowered, the active conformation of the enzyme is restored. The steady state is reached at a $\mathrm{pH}$ ranging from 5.5 to 7.5 , and inactivation is more extensive at more alkaline $\mathrm{pH}$ levels [60]. This type of inactivation can be prevented by the addition of monovalent anions, substrates, and substrate analogs and is characterized by high activation energy.

\subsubsection{Effect of Metal Ions and Enzymatic Inhibitors on the} Enzymatic Kinetics of L-Amino Acid Oxidases. Mackessy [61] fractionated the venom of Crotalus ruber ruber obtaining proteases, phosphodiesterases, and LAAOs. The activity of these enzymes, including that of the LAAOs, was inhibited in the presence of EDTA, N-ethylmaleimide, and 1,10phenanthroline, as well as PMSF and glutathione. In the presence of enzymatic inhibitors, as mentioned above, LAAO cofactors NAD or FAD are reduced, causing inactivation of the enzyme [62].

Different bivalent ions can activate or inhibit the specific activity of some LAAOs. The LAAO of Crotalus adamanteus requires $\mathrm{Mg}^{2+}$ [51], whereas the enzymes of Lachesis muta and Bothrops brazili $[59,63]$ are inhibited in the presence of $\mathrm{Zn}^{2+}$. Other ions such as manganese and calcium do not affect the activity of these enzymes. The inhibitory action of these ions might be related to their ability to reversibly bind to thiol groups of cysteines present in the active site of the enzyme, reducing its activity [64], so many pharmacological activities of sv-LAAOs are compromised in the presence of some specific ions.

3.2.3. Effect of Temperature on the Enzymatic Activity of $L$ Amino Acid Oxidases. The specific activity of some LAAOs 
depends on the experimental temperature. These enzymes remain active for a variable period of time at a broad range of temperatures $\left(0^{\circ}\right.$ to close to $\left.50^{\circ} \mathrm{C}\right)[21,24,28,30,32-$ $34,44,53,59]$. Exposure to temperatures higher than $55^{\circ} \mathrm{C}$ results in a gradual decrease in activity caused by disruptions in hydrophobic interactions and hydrogen bonds between the different subunits of the enzyme. Temperatures lower than $25^{\circ} \mathrm{C}$ are associated with increased inactivation of the enzyme $[24,28,30,33,34,59,65]$. Moreover, LAAOs are also progressively inactivated when submitted to freezing or lyophilization $[15,24,28,30,33,66]$. These types of inactivation by freezing, and also by alterations in $\mathrm{pH}$ as cited above, induce substantial conformational changes that can be demonstrated by circular dichroism [37]. These changes involve alterations in the binding of the enzyme to substrates and lack of binding to arachidonic acid (competitive inhibitor), as well as alterations in the affinity of the flavin coenzyme for electrons. Reversible inactivation by freezing involves specific regions of the catalytic site of the enzyme, affecting the redox properties of the cofactor-substrate complex $[60,67]$ and decreasing catalytic activity.

\section{Purification of L-Amino Acid Oxidases}

The first reports of isolation of LAAOs date back to the 1950s when Singer and Kearney [65] characterized an LAAO from Agkistrodon piscivorus snake venom. Later Wellner and Meister [68] obtained the crystal structure of LAAO purified from Crotalus adamanteus venom.

Snake venom LAAOs have been purified by fast and efficient chromatographic processes, including by size exclusion, ion-exchange, hydrophobic interaction, and affinity chromatographies (Table 1). A large number of these proteins have been isolated using basically the same chromatographic strategy, that is, fractionation of the venom by size exclusion chromatography, followed by hydrophobic interaction chromatography of the fractions of interest. This step can be repeated and, finally, the highly purified protein is applied to reverse-phase HPLC. However, each research group has adapted the steps of isolation to its specific protein and laboratory conditions. Numerous LAAOs have been isolated from different species: Trimeresurus mucrosquamatus [52, 69], Trimeresurus jerdonii [70], Agkistrodon halys pallas [71], Agkistrodon halys blomhoffi [72], Ophiophagus hannah [57], Lachesis muta muta [73], Naja naja kaouthia [56], and Calloselasma rhodostoma $[53,74]$. Various other LAAOs were also purified following the same steps, indicating the process efficiency (Table 1).

\section{Biochemical Characterization of L-Amino Acid Oxidases}

When analyzed under nondenaturing conditions, LAAOs are usually noncovalently linked homodimeric proteins with a molecular mass of approximately $110-150 \mathrm{kDa}$. Examples include the LAAO of Agkistrodon contortrix laticinctus [75], LAAO of Trimeresurus mucrosquamatus [69], BaltLAAO-I of Bothrops alternatus [35], CascaLAO of Crotalus durissus cascavella [31], BpirLAAO-I of Bothrops pirajai [32], LAAO of Vipera berus berus [33], LAAO of Vipera lebetina [30], Akbu-LAAO of Agkistrodon blomhoffii ussurensis [19], BmooLAAO-I of Bothrops moojeni [66], LAAO of Naja naja oxiana [28], SSAP of Sebastes schlegeli [76], Bp-LAAO of Bothrops pauloensis [24], DRS-LAAO of Daboia russelii siamensis [47], Akbu-LAAO of Agkistrodon blomhoffii ussurensis [19], BmarLAAO of Bothrops marajoensis [20], LAO Bungarus caeruleus [21], LmLAAO of Lachesis muta [15], and DrLAO of Daboia russelii [16]. When these toxins are treated under denaturing conditions, the molecular mass of each monomer determined by mass spectrometry is about 50-70 kDa (Table 1).

This variation in molecular mass among different LAAOs might be related to the sites of glycosylation since these enzymes are considered to be glycoproteins $[14,24,28,30,32-$ $35,66,69,77,78]$. The association of carbohydrates with the structure of LAAOs was first detected by the method described by Lowry et al. [79]. This class of enzymes is characterized by a variable percentage of sugars which vary according to snake species: $4 \%$ in Calloselasma rhodostoma, $2.64 \%$ in Bothrops brazili, 3.6\% in Bothrops jararaca, 2 to $5 \%$ in Crotalus adamanteus, $15 \%$ in Bothrops alternatus, $13-$ $16 \%$ in Bothrops moojeni, $12 \%$ in Bothrops atrox, and, $25 \%$ in Bungarus caeruleus $[21,25,35,53,59,66,80,81]$, respectively. Some carbohydrates such as fucose, mannose, galactose, NAcetylglucosamine, and sialic acid have been identified as associated with these enzymes, accounting for approximately $5.4 \%(\mathrm{w} / \mathrm{w})$ of total proteins $[59,82,83]$. These sugars are linked to the enzyme through $\mathrm{N}$-glycosidic bonds and probably modulate its physicochemical properties, increasing the solubility and viscosity of the protein and maintaining the stability of electrical charges $[34,66]$. Studies have demonstrated that some LAAOs do not lose their catalytic activity after deglycosylation assays using $\mathrm{O}$-glycosidase and PNGase F [24, 27, 32, 35, 66, 78], a finding suggesting that the carbohydrate moiety of the enzyme only plays a structural role or protects the enzyme against proteolysis since snake venoms are rich in proteolytic enzymes [84].

Most LAAOs described so far are variably acidic, with isoelectric points above 4.4 (Table 1). In contrast, some LAAOs are slightly basic and present an isoelectric point of 8.0 or higher, including the LAAO of Trimeresurus flavoviridis with a pI of 8.4 [29], LAAO of Naja naja kaouthia with a pI of 8.1 [85], LAAO of Agkistrodon acutus with a pI of 8.2 [86], and LAAO of N. naja oxiana with a pI $>8$ [28]. Isoforms of the same LAAO are often present in the same venom, which can be acidic, neutral, or basic [87]. This difference in charge density may alter the pharmacological activities of LAAOs as observed with other snake venom enzymes.

\section{Antigenicity of L-Amino Acid Oxidases}

In general, snake venoms are strong antigenic inductors due to their high protein content. The variability in snake venom composition raises an additional problem for the production of antivenom serum and thus provides a commercial incentive for the manufacturers of therapeutic agents against ophidian envenomation. Particularly, inter- and intraspecific 
TABLE 3: Sequence of snake venom L-amino acid oxidase deposited in the NCBI database.

\begin{tabular}{lcccc}
\hline Family & Snake & bp $^{*}$ & gi & Reference \\
\hline Viperidae & B. . pauloensis & 1519 & 195927837 & ND \\
Viperidae & Bothrops jararaca & 1452 & 33355626 & {$[24]$} \\
Viperidae & Viridovipera stejnegeri & 1551 & 38000585 & {$[27]$} \\
Viperidae & Bitis gabonica & 180 & 398441345 & {$[111]$} \\
Viperidae & Bothrops moojeni & 1436 & 398441343 \\
Viperidae & Bothrops jararacussu & 1491 & 3426323 & {$[22]$} \\
Viperidae & Crotalus adamanteus & 2787 & 126035652 & 126035676 \\
Elapidae & Bungarus fasciatus & 2815 & 126035648 \\
Elapidae & Naja atra & 2794 & 126035643 \\
Elapidae & Bungarus multicinctus & 2883 & {$[95]$} \\
Elapidae & Ophiophagus hannah & & {$[14]$} \\
\hline
\end{tabular}

ND: not determined. *bp: base pairs.

variations in snake venom composition have been demonstrated to affect the neutralization capacity of antivenom sera [88].

Various studies have been carried out to develop alternative methods to improve neutralization of the toxic effects of snake venom envenomation. Our knowledge about immunological cross-reactivity of venoms has evolved from experimental evidence obtained using different approaches. The phenomenon of cross-reactivity between snake venoms is related to the observation that antiserum specifically prepared against the venom of one type of snake may react with other snake venoms [89]. Studies on the cross-reactivity of snake venoms suggest the apparent lack of a correlation between cross-reactions and phylogeny, implying that the results obtained based on antigen recognition do not completely reflect the molecular evolution of snake venoms $[90,91]$. The specificity of snake venom antibodies against a fragment of Bothrops moojeni LAAO shows that crossreactivity is mediated, at least in part, by antibodies that are able to recognize another functional protein [92]. This difficulty in neutralizing venoms is mainly related to the damage at the site of the bite.

\section{Structural and Molecular Characteristics of L-Amino Acid Oxidases}

The development of recombinant DNA techniques and nucleotide and amino acid sequencing has permitted the creation of databases that are shared by various researchers in order to identify the composition of each venom and the key activities of each protein. The N-terminal amino acid sequences of various LAAOs from the snake families, Viperidae and Elapidae, were deduced by Edman degradation, and alignment of these sequences always showed a high identity, even when toxins originating from distinct snake species were compared [31, 32, 35, 75, 83, 93, 94]. cDNA analysis using yeast or Escherichia coli as expression vectors showed that partial sequences of venom LAAOs from different snake species also present highly conserved regions along the primary structure of the protein, characterizing high identity between these enzymes $[14,24,27,34,66,72,75,95]$. The number of base pairs of these sequenced toxins is highly variable, and most sequences are deposited in the NCBI database (Table 3).

Macheroux et al. [37] deduced the complete sequence of Calloselasma rhosdostoma LAAO from cDNA, with the sequence showing a high identity with LAAOs from Crotalus adamanteus and Crotalus atrox.

cDNA sequencing of LAAOs provides important information for the structural understanding of this class of still poorly explored enzymes. Ali et al. [83] demonstrated the presence of a highly conserved $\beta \alpha \beta$-fold domain in the $\mathrm{N}$ terminal region of an LAAO from Eristicophis macmahoni venom, which is responsible for binding the FAD cofactor. Zhang et al. [86] identified a change to asparagine in the second amino acid residue of the N-terminal region of AHPLAAO from $A$. halys pallas venom, which might play an important role in enzymatic activity since this region is involved in many effects induced by the enzyme.

Multiple alignment of the primary structure of a Calloselasma rhodostoma LAAO showed a high similarity (>84\%) with other snake venom LAAOs (Table 4). Phylogenetic comparisons between FAD-dependent snake venom LAAOs and other FAD-dependent oxidases, such as monoaminoxidase (MAO), D-amino acid oxidase, and tryptophan 2monooxygenase, reveal only distant relationships. However, all LAAOs share a highly conserved dinucleotide-binding region with $\mathrm{MAO}, \mathrm{D}$-amino acid oxidase, tryptophan 2monooxygenase, and various other proteins that may also require FAD [37].

Sequences of LAAOs were aligned and analyzed according to the region of the world. The results of the alignment are shown in order of alignment (Figure 2). Most dissimilar regions were found in the $\mathrm{C}$ - and $\mathrm{N}$-termini, and higher conservation between sequences was seen in the territories that were occupied more recently by humans (North America and South America). The percentage of global alignment resulted in $\sim 60 \%$ similarity.

In the phylogenetic tree (Figure 3), four groups may be distinguished: first South America; second North America and the New World; third China, Japan, and Korea; and 
TABLE 4: Percent of similarity between L-amino acid oxidases from snake venoms.

\begin{tabular}{lcccccccccc}
\hline Sequences & GI & $(1)$ & $(2)$ & $(3)$ & $(4)$ & $(5)$ & $(6)$ & $(7)$ & $(8)$ & $(9)$ \\
\hline Calloselasma rhodostoma & 20141785 & 100.00 & 85.36 & 85.99 & 88.27 & 88.76 & 89.48 & 86.63 & 84.69 & 88.32 \\
Bothrops moojeni & 82127389 & 85.36 & 100.00 & 87.39 & 88.77 & 88.70 & 88.49 & 86.40 & 95.82 & 88.08 \\
Crotalus adamanteus & 6093636 & 85.99 & 87.39 & 100.00 & 87.19 & 87.94 & 87.65 & 85.41 & 87.35 & 87.67 \\
Agkistrodon halys & 48425312 & 88.27 & 88.77 & 87.19 & 100.00 & 91.77 & 99.18 & 90.95 & 90.12 & 90.74 \\
Ovophis okinavensis & 538260091 & 88.76 & 88.70 & 87.94 & 91.77 & 100.00 & 92.66 & 89.53 & 88.95 & 92.67 \\
Gloydius blomhoffii & 75570145 & 89.48 & 88.49 & 87.65 & 99.18 & 92.66 & 100.00 & 91.67 & 91.07 & 91.47 \\
Trimeresurus stejnegeri & 33355627 & 86.63 & 86.40 & 85.41 & 90.95 & 89.53 & 91.67 & 100.00 & 86.24 & 91.49 \\
Bothropoides pauloensis & 347602324 & 84.69 & 95.82 & 87.35 & 90.12 & 88.95 & 91.07 & 86.24 & 100.00 & 91.09 \\
Protobothrops flavoviridis & 538259837 & 88.32 & 88.08 & 87.67 & 90.74 & 92.67 & 91.47 & 91.49 & 91.09 & 100.00 \\
\hline
\end{tabular}

fourth Australia and India. The sequence gi|327266254 Anolis_Root_Tree is an LAAO of the lizard Anolis carolinensis that was included for the control protocol. Phylogenetic analyses were run using the website http://www.phylogeny.fr/ [96]. Sequences were aligned using the MUSCLE program [97] according to the mer distances clustered by UGPMA. The Gblocks program [98] was used to eliminate poorly aligned positions and divergent regions. PhyML 3.0 was used for phylogenies [99] including substitution models WAG for proteins. The ALTR test ( $\mathrm{SH}$-like) was used to access the support values of each branch [100].

Generally, the composition of LAAOs is quantitatively similar, with many asparagine, glutamic acid, and aspartic acid residues and few methionine and tryptophan residues. The number of cysteine residues varies, indicating variations in the tertiary structure of these enzymes $[35,83,102]$.

The cDNA-deduced sequence of various snake LAAOs is characterized by the presence of a highly conserved $\beta \alpha \beta$ domain in the $\mathrm{N}$-terminal region that is rich in glutamic acid residues and possibly functions as a binding site for the FAD cofactor, which is fundamental for the generation of hydrogen peroxide $[37,94]$. Indeed, determination of the N-terminal region of LNV-LAAO isolated from Eristicophis macmahoni venom by Ali et al. [103] showed similarity with other snake venom LAAOs in terms of the large number of glutamic acid residues found in this region, suggesting an important functional role of the $\mathrm{N}$-terminal region of these enzymes $[31,35]$.

The structure of LAAO from Calloselasma rhodostoma was determined in the presence of the ligands citrate, aminobenzoate, and phenylalanine. This analysis showed that the protein consists of three domains: an FAD-binding domain, a substrate-binding domain, and an $\alpha$-helical domain (Figure 4). The interface between the $\alpha$-helical domain and the substrate-binding domain forms a $25 \AA$ long funnel, which provides access to the active site. Three aminobenzoate molecules are visible along the funnel, a finding suggesting the trajectory of the substrate to the active site.

The innermost aminobenzoate molecule forms a hydrogen bond with the active site residues, Arg90 and Gly464, and the aromatic portion of the ligand is located in a hydrophobic region. These interactions mimic binding of natural substrates.
Analysis of the surface of the Calloselasma rhodostoma LAAO active site showed that the recess has a long Y-shape which allows the substrate to interact with the enzyme in such a way that one portion of the input channel interacts with $\mathrm{O}_{2}$, and the other is where product release occurs [50]. According to these authors, the active site is dynamic and can undergo conformational changes due to the presence of two amino acid residues, His 223 and Arg322. Both residues are located along the driveway to the substrate to the active center. These amino acids can take on two different conformations (A and B), and the $\mathrm{His}_{223}$ spends $40 \%$ of its time as conformation $\mathrm{A}$ and $60 \%$ as $\mathrm{B}$. The $\mathrm{His}_{223}$ conformation $\mathrm{A}$ has an imidazole side chain group which is stabilized with the aid of a water molecule through hydrogen bonding with its neighbors $\mathrm{Glu}_{209}$ and $\mathrm{Ser}_{220}$. In conformation $\mathrm{B}$, the imidazole ring is attached to a neighboring phenyl group at a distance of 3.1 A. The lack of hydrogen bonding with neighboring side chains increases the mobility of this residue. The movements of the imidazole ring of the side chain are probably related to the mechanism of deprotonation of the substrate. Minor conformational changes are observed for $\operatorname{Arg}_{322}$. The two types of conformation of arginine differ in the position of carbons $\mathrm{C} \delta$ and $\mathrm{C} \gamma$ depending on angles between $-84^{\circ}$ and $73^{\circ}$ and the conformation to B.

The position of the guanidine group of the side chain is similar in both conformations, with the $\mathrm{N} \varepsilon$ stabilized through hydrogen bonding with the hydroxyl of $\mathrm{Thr}_{432}$. The guanidine group may also interact with the side chains of amino acids $\mathrm{Glu}_{209}$ and $\mathrm{Glu}_{219}$, making them stable. The movements observed in the side chain of $\mathrm{His}_{223}$ and $\mathrm{Arg}_{322}$ may be associated with the attachment and release of the substrate and product, respectively.

According to Moustafa et al. [50], during the binding of the substrate to the catalytic site of the enzyme, $\mathrm{His}_{223}$ assumes conformation A, blocking the entry of oxygen, thus allowing for the entry of the substrate. When the chemical reaction happens, $\mathrm{His}_{223}$ assumes conformation $\mathrm{B}$ again, unlocking the entry of oxygen to release the product. The movements in the side chain of $\mathrm{Arg}_{322}$, which change the conformation from form $A$ to form $B$, are favorable hydrophobic interactions occurring between the aliphatic amino acid side chain and the aromatic ring of the enzyme substrate. After the enzymatic reaction occurs, it returns to form $B$ to facilitate 
6093636_North_America 124106294_New_World 401021343_New_World 347602324_South_America 82127391_South_America 60729671_China 33355627_China 75570145_China_Japan_Korea 123916679_Australia 347602325_India

6093636_North_America 124106294_New_World 401021343_New_World 347602324_South_America 82127391_South_America 60729671_China 33355627_China 75570145_China_Japan_Korea 123916679_Australia 347602325_India

6093636_North_America 124106294_New_World 401021343_New_World 347602324_South_America 82127391_South_America 60729671_China 33355627_China 75570145_China_Japan_Korea 123916679_Australia 347602325_India

6093636_North_America 124106294_New_World 401021343_New_World 347602324_South_America 82127391_South_America 60729671_China 33355627_China 75570145_China_Japan_Korea 123916679_Australia 347602325_India

6093636_North_America 124106294_New_World 401021343_New_World 347602324_South_America 82127391_South_America 60729671_China 33355627_China 75570145_China_Japan_Korea 123916679_Australia 347602325_India

6093636_North_America 124106294_New_World 401021343_New_World 347602324_South_America 82127391_South_America 60729671_China 33355627_China 75570145_China_Japan_Korea 123916679_Australia 347602325_India $\begin{array}{rrrrrr}10 & 20 & 30 & 40 & 50 & 60 \\ \mid & \mid & \mid & \mid & \mid\end{array}$ MNVFFMFSLLFLAALGSCAHDR-NPLEECFRETDYEEFLEIAKNGLTATSNPKRVVIVGA MNVFF.FS . . . ALG.C...R-N. E. . . . . . . . . . . . . . . . MNVFF.FS . . . ALG.C..R-N. . G. . . . . . . . . RA. . . . . .

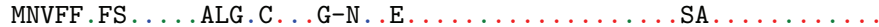
---- .NV . . . . KPG.L. . R-N. .E. . . . . . . . . . . . . . . . . .

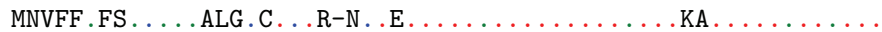
MNVFF.FS . . . ALE.C..R-N. E. . . . . . . . . KA. . . . . MNVFF.FS . . . ALG.C. . R-N. E. . . . . . . . . KA . . . . . . . MNVFF.FS . . . ALG.C. . RRR. E. . . . . . . . . . . . . . . . MNVFS.FS . . . AFG.C. . RRS. E. . . . . . . . . KK . . . . . . $\begin{array}{cccccc}70 & 80 & 90 & 100 & 110 & 120 \\ \text { GMAGLSAAYVLAGAGHQVTVLEASERVGGRVRTYR--KKDWYANLGPMRLPTKHRIVREY }\end{array}$ $\ldots \ldots \ldots \ldots$. . . . . . . . . . . . . . . . . . . . $\ldots \ldots \ldots \ldots$ E. . . . . . . . . . . . . E. . E. $\ldots \ldots \ldots \ldots$. . . . . . . . . . . . . . . E . . E

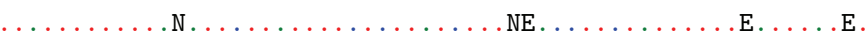

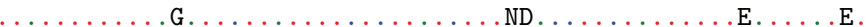

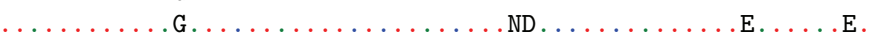

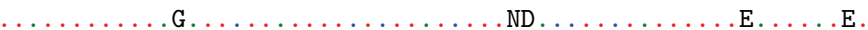
$\ldots \ldots \ldots \ldots$ G. . . . . . . . . . . . . . E E. E.

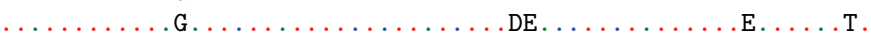

$\begin{array}{llllll}130 & 140 & 150 & 160 & 170 & 180\end{array}$

IKKFDLKLNEFSQENENAWYFIKNIRKRVREVKNNPGLLEYPVKPSEEGKSAAQLYVESL

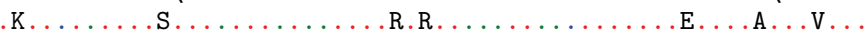
R......H.........R.G.........E...G..E.. R......S..........R.G..................... R......S.........R.G..........V...G..E..

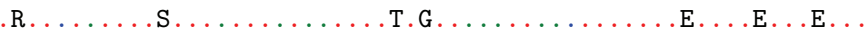

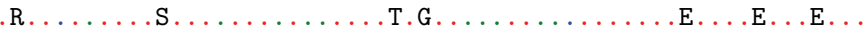

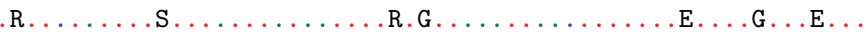

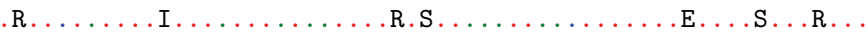

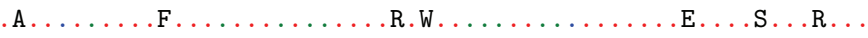
$\begin{array}{lllll}190 & 200 & 210 & 220 & 230\end{array}$ RKVVEELRSTNCKYILDKYDTYSTKEYLLKEGNLSPGAVDMIGDLLNEDSGYYVSFIESL

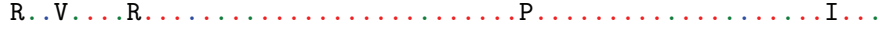

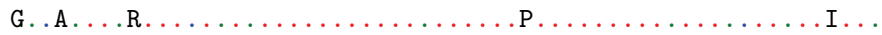

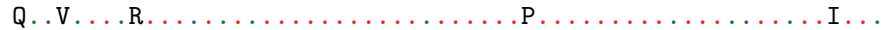

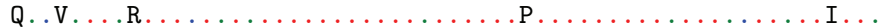

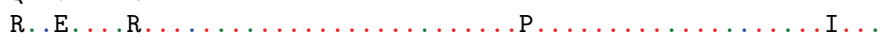

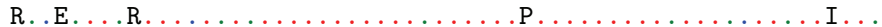

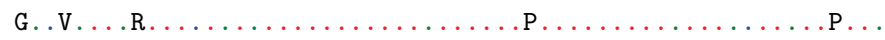

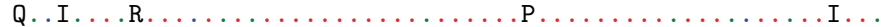

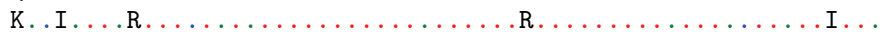
$\begin{array}{rrrrr}250 & 260 & 270 & 280 & 290\end{array}$ KHDDIFGYEKRFDEIVGGMDQLPTSMYEAIKEKVQVHFNARVIEIQQNDREATVTYQTSA . $\mathrm{H} \ldots \ldots \ldots$. . . V . . . . . . . . K.K. VH . . . . . . . . T . . . A

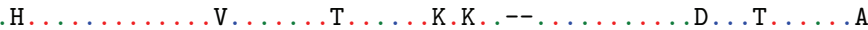

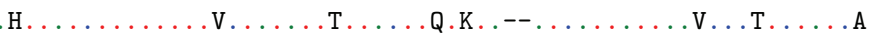
H........V.....T....Q.K..-......V... . . . E

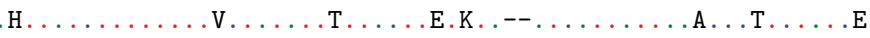

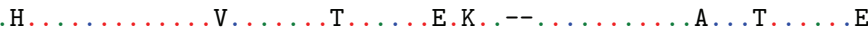

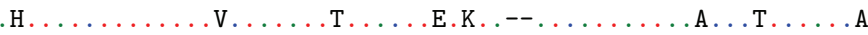

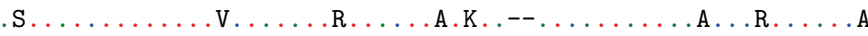

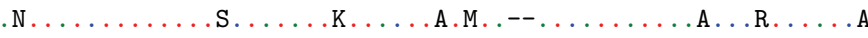
$\begin{array}{rrrrrr}310 & 320 & 330 & 340 & 350 & 360 \\ \mid & \mid & \mid & \mid & \mid\end{array}$ NEMSSVTADYVIVCTTSRAARRIKFEPPLPPKKAHALRSVHYRSGTKIFLTCTKKFWEDD EMSS.T . . . . . . . . . K. . . P . . . . . . . . . . . .W.D. .EMSP.T. . . . . R. . T. . . . . . . . . . . . . . . . D. ETLS.T......R....K....P.................. .ETLS.T. . . . . R. . . . . . . . . . . . . . . . . . . . . .

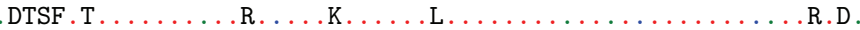

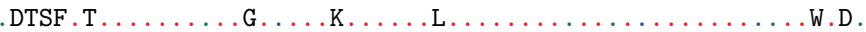

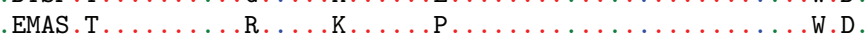

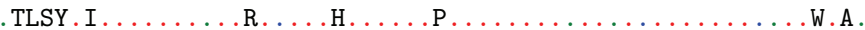
TLSY.T......R....S....P..................

(a)

Figure 2: Continued. 


6093636_North_America
124106294_New_World
401021343_New_World
347602324_South_America
82127391_South_America
60729671_China
33355627_China
75570145_China_Japan_Korea
123916679_Australia
347602325_India

6093636_North_America 124106294_New_World 401021343_New_World 347602324_South_America 82127391_South_America 60729671_China 33355627_China 75570145_China_Japan_Korea 123916679_Australia 347602325_India

6093636_North_America 124106294_New_World 401021343_New_World 347602324_South_America 82127391_South_America 60729671_China 33355627_China 75570145_China_Japan_Korea 123916679_Australia 347602325_India

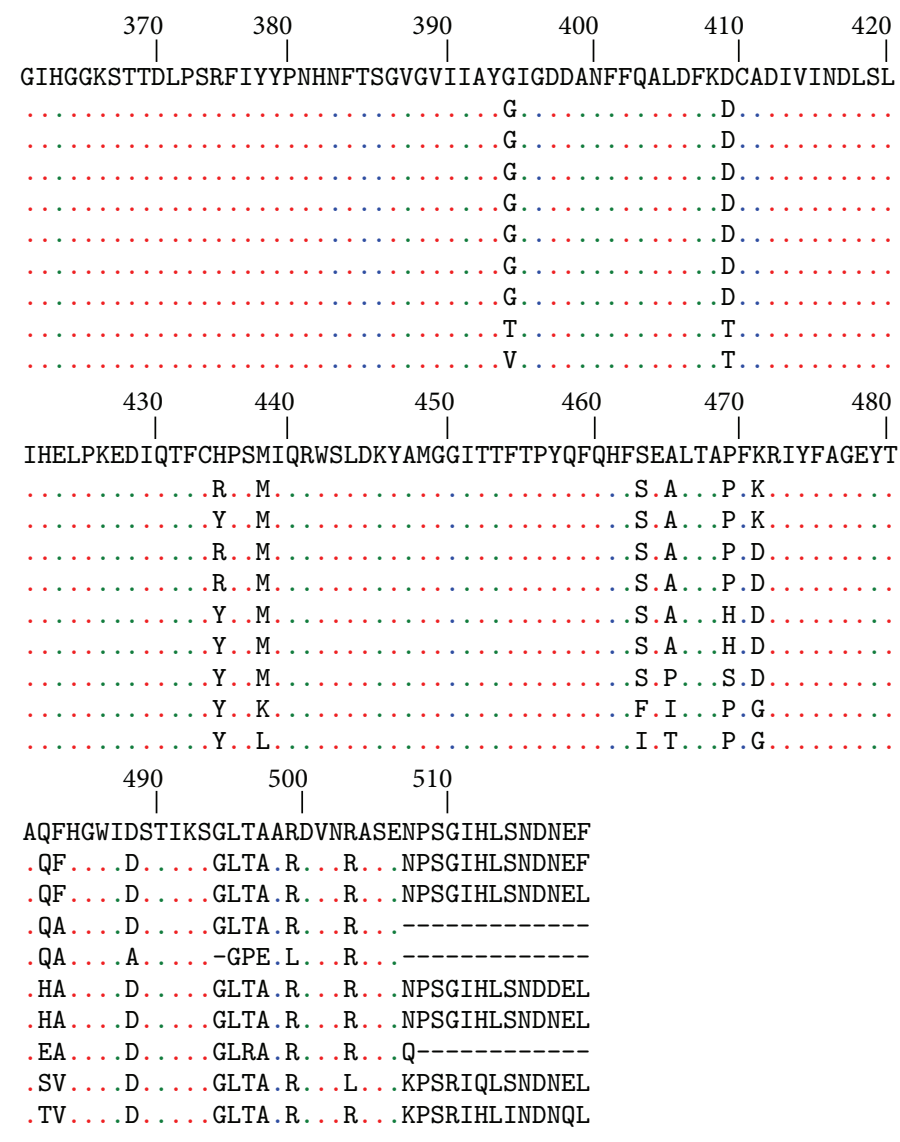

(b)

FIGURE 2: Sequence alignment of L-amino acid oxidases from snake venoms of some regions of the world. The alignment was performed using the program ClustalW [101]. Only nonconserved amino acids are showed.

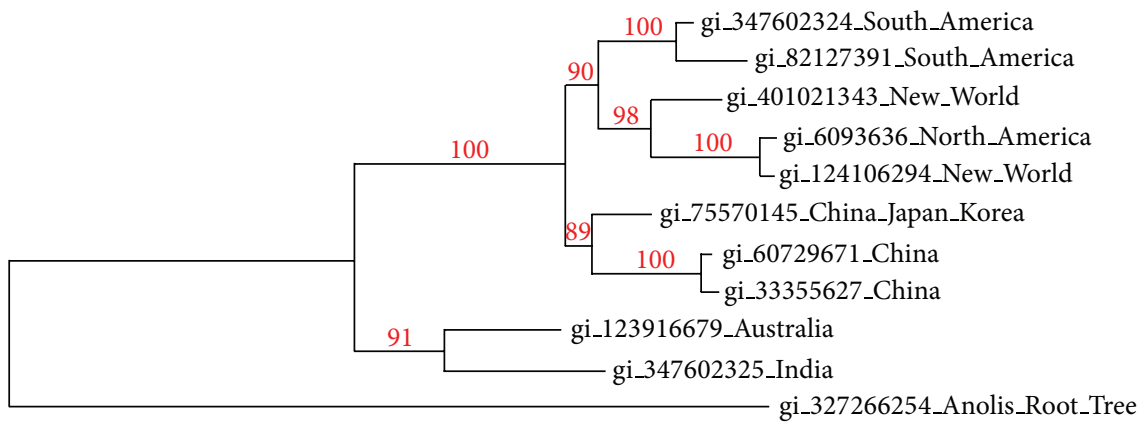

0.2

Figure 3: Phylogenetic representation of amino acid sequence alignments of L-amino acid oxidases from snake venoms of some regions of the world. Trees were obtained as described in the Methods section at http://www.phylogeny.fr/. Numbers close to the nodes represent the support value for each branch. The region of the world is shown after the accession numbers. The sequence gi|327266254_Anolis_Root_Tree is the root control of the tree.

the release of the product. The interaction of the substrate with the active site of the enzyme is mediated by the guanidine group of Arg90 and hydrogen bonding with the hydroxyl of $\mathrm{Tyr}_{372}$. The amino group of the substrate forms hydrogen bonds with the carbonyl oxygen atom of the $\mathrm{Gly}_{464}$ residue, and then the side chains of the ligands form hydrophobic interactions with the side chains of $\mathrm{Ile}_{430}$ and $\mathrm{Ile}_{374}$ and $\mathrm{Phe}_{227}$. One of the two oxygen atoms of the carboxylic group of the substrate becomes involved with a water molecule by hydrogen bonding with the flavin N-5, as well as 


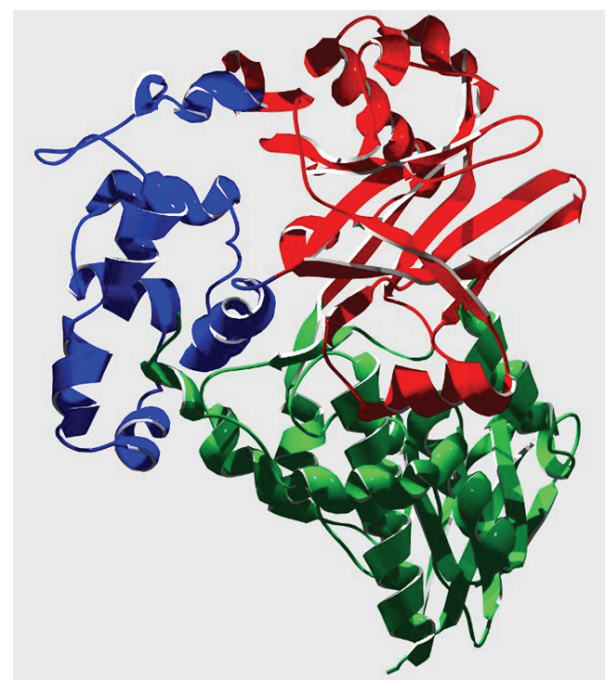

FIgURE 4: Structure of LAAO from Calloselasma rhodostoma (PDB code 2IID) with a resolution of $1.80 \AA$ [50]. The structure was shown in ribbon representation using Swiss-PDBViewer software with renderization POV-ray [104]. In blue is the $\alpha$-helical domain, in red is the substrate-binding domain, and in green is the FADbinding domain.

the amino group of the side chain of Lys $_{326}$. Thus, the $\alpha$ carbon undergoes oxidative attack, generating the product.

Comparisons between the structure of snake venom LAAOs and mammalian D-amino acid oxidases reveal significant differences in the way the substrate arrives at the active site. In addition, a mirror-symmetrical relationship between the two substrate binding sites is observed, which facilitates enantiomer selectivity while the arrangement of atoms involved in catalysis is preserved [102].

\section{Biological Effects of L-Amino Acid Oxidases}

Since the 1950s when the isolation of different snake venom LAAOs from different species was initiated, studies to identify their activities and to understand their mode of action have also increased. As a result, different assays for the characterization of the toxic and pharmacological effects of these enzymes were standardized to obtain a better understanding. Until the 1990s, studies were restricted to the investigation of the structural and functional characteristics of these enzymes [4], whereas today in vitro and in vivo studies allow for a broader characterization and understanding of their effects and medical and pharmacological importance.

A range of researchers have characterized the functional properties of crude venoms from different snakes and observed that many of their toxic and pharmacological activities can be attributed to LAAOs [11, 100, 102, 105]. Comparative studies analyzing different snake venoms have demonstrated distinct effects induced by venoms that contain LAAO to a greater or lesser extent [106, 107]. Many of these effects seem to be related, at least in part, to hydrogen peroxide, a secondary product formed during the chemical reaction catalyzed by LAAOs. Du and Clemetson [4] reported a lack of evidence explaining such data, but different studies confirm that the addition of catalase in the presence of LAAOs completely suppresses the toxic effects of these enzymes $[14,20,21,24,25,27,28,30-34,47-49,66,76-$ $78,95]$.

\subsection{Local Alterations Induced by L-Amino Acid Oxidases}

8.1.1. Hemorrhage. The classical route of induction of hemorrhagic processes by snake venoms involves the degradation of extracellular matrix proteins of vascular endothelium. Souza et al. [75] proposed that snake venom LAAOs trigger a process of apoptosis in vascular endothelial cells, causing rupture of the endothelium and concomitant leakage of blood to the interstice. A few LAAOs isolated from snake venoms are able to induce hemorrhage, including ACL-LAO from Agkistrodon contortrix laticinctus [75], Balt-LAAO-I from Bothrops alternatus [35], ABU-LAO from Agkistrodon blomhoffii ussurensis [29], and BatroxLAAO from Bothrops atrox [25].

8.1.2. Edema. The edematogenic activity of snake venoms is explained by an increase in vascular permeability that results in the leakage of fluid from blood vessels to the interstitial space of tissues. Some LAAOs have been described as edematogenic, including LNV-LAAO from Eristicophis macmahoni [83], TM-LAO from Trimeresurus mucrosquamatus [108], Balt-LAAO-I from Bothrops alternatus [35], BpirLAAO-I from Bothrops pirajai [32], ABU-LAO from Agkistrodon blomhoffii ussurensis [29], BmooLAAO-I from Bothrops moojeni [66], BatroxLAAO from Bothrops atrox [25], BF-LAAO from Bungarus fasciatus [55], and DrLAO from Daboia russelii [16].

Few studies have been conducted to determine the true mode of action of LAAOs in the induction of edema compared to other classes of snake toxins. Studies investigating different snake toxins revealed that the action of these compounds is related to the stimulation and release of inflammatory mediators such as histamine, prostaglandin, kinins, and serotonin [103]. On the other hand, the edematogenic activity of LAAOs does not seem to be mediated by the mechanisms described for other toxins since these enzymes do not lose their activity in the presence of antihistamines. Indeed, Ali et al. [103] observed that the edematogenic activity of Ophiophagus hannah LAAO was not inhibited in the presence of dexamethasone. However, the activity of this enzyme was completely suppressed when treated with glutathione, indicating that edema induced by LAAO is directly related to the presence of hydrogen peroxide.

\subsection{Systemic Alterations Induced by L-Amino Acid Oxidases}

8.2.1. Platelet Aggregation. The activity of LAAOs on platelets is still controversial, with a variable potential of these enzymes to inhibit or induce platelet aggregation. LAAOs isolated from the venoms of Echis coloratus [109], A. $h$. blomhoffii [72], Vipera berus berus [33], Vipera lebetina [30], 
Bothrops leucurus [17], Ophiophagus hannah [14], Agkistrodon blomhoffi ussurensis [29], Naja naja oxiana [28], and Daboia russelii siamensis [47] present inhibitory activity on platelet aggregation. Du and Clemetson [4] believe that hydrogen peroxide released by enzymatic action may interfere with the interaction between platelet receptors (GPIIb/IIIa) and fibrinogen, thus impairing the mechanism of aggregation. According to Zhong et al. [47], hydrogen peroxide produced during the catalytic reaction plays a fundamental role in the inhibition of platelet function, but the exact mechanism is still unclear. On the other hand, studies have shown the ability of various LAAOs to induce platelet aggregation [21, $24,25,31,32,35,46,69,70]$. However, this effect was always suppressed in the presence of catalase, indomethacin, and/or aspirin. Thus, the authors suggested that hydrogen peroxide production during oxidation of the substrate is related to this activity. In addition, the possible inhibition of endogenous $\mathrm{PLA}_{2}$ may play an important role in platelet aggregation. According to Sakurai et al. [85], the controversial results reported might be associated with differences in experimental procedures or plasma preparation.

Nathan et al. [109] demonstrated that the LAAO isolated from $O$. hannah venom induces platelet aggregation. The authors proposed that this effect may not be dependent on ADP but requires thromboxane $\mathrm{A}_{2}$ since they observed no change in aggregation activity when the creatine phosphokinase/creatine phosphate system, which consumes ADP, was added. In contrast, platelet aggregation was inhibited when aspirin and indomethacin were added in the presence of this LAAO. Catalase and EDTA also inhibited the activity of the enzyme. The authors therefore suggested that the induction of platelet aggregation by this enzyme is intimately related to the formation of hydrogen peroxide and the subsequent synthesis of thromboxane $\mathrm{A}_{2}$ which requires $\mathrm{Ca}^{2+}$, independent of the release of ADP. According to Zhong et al. [47], the role of hydrogen peroxide in the process of inducting platelet aggregation remains uncertain since recent studies indicate that it is unlikely that hydrogen peroxide alone is responsible for the biological activities of LAAOs; that is, other mechanisms are probably triggered and cause a potent biological response.

8.2.2. Effects on Blood Coagulation. Alterations in blood coagulation induced by snake venoms have also been the target of many studies conducted in Brazil since the 1960s. This is not only due to the large amount of snake bites, but also because these venoms have become tools for the study of the complex processes involved in blood coagulation. These venoms are also used as auxiliary tools for clinical diagnosis and as therapeutic agents to provoke defibrinogenation during thrombosis treatment. Li et al. [110] isolated an LAAO from Agkistrodon halys blomhoffii venom, referred to as M-LAO, which presented high anticoagulant potential. This enzyme was found to inhibit the activity of factor IX, involved in the process of coagulation, in a time- and dosedependent manner. M-LAO showed the same anticoagulant potential when membrane phospholipids were added, thus demonstrating that its inhibitory activity is directly related to the depletion of factor IX activity, destabilizing the intrinsic pathway of blood coagulation.

\section{Pharmacological Effects of L-Amino Acid Oxidases}

9.1. Antiviral Effect of L-Amino Acid Oxidases. The antiviral effect of LAAOs has yet to be well explored. One study reports the possible inhibition of HIV-1 replication by an LAAO isolated from Trimeresurus stejnegeri venom, called TSVLAO [112]. This activity was demonstrated by a reduction in protein p24 production, which indicates HIV-1 replication and a decrease in syncytium formation. TSV-LAO was unable to block the fusion between HIV-1 and host cells, suggesting that this enzyme does not interfere with the absorption and/or binding of the virus to the host cell.

The antiviral potential of LAAOs was also studied by Sant'Ana et al. [27], who treated cells infected with DENV-3 virus strains, the etiological agent of dengue, with BjarLAAOI isolated from Bothrops jararaca snake venom. The treatment's efficiency was demonstrated by a reduction of viral load in previously infected C6/36 cells exposed to the toxin when compared to controls of unexposed infected cells.

9.2. Antiparasitic Effect of L-Amino Acid Oxidases. Inhibitory activities on the growth of Trypanosoma cruzi and Leishmania donovani infantum or other species of Leishmania have been reported for different snake venoms [113]. This antiparasitic effect might be attributed to the activity of LAAOs $[4,15,17,20,24,27,31,32,66,78,83,95,114]$.

Leishmaniasis is caused by parasites of the genus Leishmania spp. and is transmitted to the vertebrate host through the bite of mosquitoes of the genera Lutzomyia (Old World) and Phlebotomus (New World). Clinical manifestations observed in patients vary according to parasite species, with these parasites being widely distributed in tropical and subtropical regions worldwide. Leishmaniasis comprises a broad spectrum of infectious complications ranging from skin ulcerations to progressive and lethal visceral infections [115]. The first-line drugs for the treatment of this disease are pentavalent antimonials, which have serious side effects and to which the target parasites have shown clinical resistance. Thus, the study of new antiparasitic compounds from different sources, including those with antileishmanial activity, is of biotechnological and medical interest.

Chagas disease is caused by the parasite Trypanosoma cruzi and is transmitted by the vector Triatoma infestans ("barbeiro"). Epimastigotes are the potentially infectious form. The most common clinical manifestation observed during the chronic phase is cardiomyopathy, which often leads to death of the patient.

The leishmanicidal/trypanocidal effect of LAAOs purified from snake venoms is due to the oxidative stress induced by hydrogen peroxide in infected cells, resulting in proteolytic activity in treated cells. Subsequently, the mitochondrial function of these cells is compromised due to calcium influx, activating other enzymes such as nitric oxide synthetase and phospholipases. These events culminate in an increased 
production of free radicals and consequent destruction of genetic material, with the cell entering apoptosis [116].

An LAAO isolated from B. moojeni venom presented leishmanicidal activity against promastigote forms of Leishmania amazonensis five times higher than that of the crude venom $[66,113]$. However, this enzyme showed no activity when tested against amastigote forms, suggesting that this parasite possesses an effective protection system against free radicals and hydrogen peroxide. Pessatti et al. [117] discussed the possibility that while the promastigote is totally deficient in catalase and glutathione peroxidase, the amastigote accumulates high concentrations of the antioxidant enzymes catalase and superoxide dismutase, which were susceptible to the action of the secondary metabolite formed during the oxidation of L-amino acids, justifying effective leishmanicidal activity of this class of toxins.

Murray [118] showed that amastigote forms of Leishmania donovani contain three times more catalase and 14 times more glutathione peroxidase than promastigote forms and are therefore four times more resistant to the enzymatic production of hydrogen peroxide, which raised several studies.

Various researchers have attributed the antiprotozoan potential of LAAOs to hydrogen peroxide since the effect disappeared when the enzyme was incubated with catalase $[24,27,31,32,66,78,95]$. A similar explanation was provided for the trypanocidal effect of LAAOs $[27,66,95]$. svLAAOs may be involved in several other pharmacological activities.

\subsection{Bactericidal Effect of L-Amino Acid Oxidases. Since} Skarnes [119] observed, for the first time, the bactericidal potential of an LAAO isolated from Crotalus adamanteus venom, many other snake venom LAAOs have been shown to be effective against bacteria, irrespective of the genus from which they were isolated: Trimeresurus jerdonii [70], Trimeresurus mucrosquamatus [69], Bothrops alternatus [35], A. halys [86], Crotalus durissus cascavella [31], Vipera lebetina [30], Bothrops pirajai [32], Bothrops moojeni [66], Naja naja oxiana [28], Bothrops pauloensis [24], Bothrops jararaca [78], Daboia russelii siamensis [47], Agkistrodon blomhoffii ussurensis [19], Bothrops marajoensis [20], Ophiophagus hannah [120], Calloselasma rhodostoma and Ophiophagus hannah [18], and Crotalus durissus cumanensis [12].

The true bactericidal mode of action of LAAOs is still not completely understood but seems to be related to the oxidized form of the cofactor of the enzyme (FAD or FMN). This cofactor interacts with L-amino acids that can then act on nucleic acids, proteins, and the plasma membrane. Thus, when in contact with the bacterial membrane hydrogen peroxide can provoke lipoperoxidation [13, 31, 49], DNA fragmentation $[29,32,75]$, and consequent cell death. The probable mechanisms induced by LAAOs on proteins involve the enzymatic oxidation of L-amino acids [36].

According to Zhang et al. [86] inhibitory activity of AHPLAAO isolated from $A$. $h$. pallas venom on the growth of Bacillus subtilis (Gram-positive) and E. coli (Gram-negative) was observed. When treated with L-vinylglycine, a substrate that reversibly inhibits the oxidative activity of LAAO [121], the enzyme completely lost its bactericidal activity. The same was observed in the presence of catalase. The authors suggested that the bactericidal activity of AHP-LAAO is related to its oxidative potential. Since L-vinylglycine is a substrate that interacts with the catalytic site of LAAOs and not with the glycan moiety, the loss of bactericidal activity in the presence of this substrate indicates that the presence of carbohydrates is not fundamental for this activity.

The LAAO isolated from Crotalus durissus cascavella venom by Toyama et al. [31], called CascaLAO, presented bactericidal activity against Xanthomonas axonopodis pv. passiflorae (Gram-negative) and Streptococcus mutans (Grampositive). This activity was demonstrated using transmission electron microscopy by rupturing the plasma membrane of microorganisms and observing consequent leakage of cytoplasmic content and cell death. An immunohistochemical study also demonstrated that achacin, an LAAO purified from Achatina fulica [26], binds to the plasma membrane of Staphylococcus aureus and E. coli during the growth phase, causing death of the bacteria by the mechanisms mentioned above.

According to several investigators [31, 76, 86, 122], the most likely mode of action involved in the bactericidal activity of LAAOs is that hydrogen peroxide causes oxidative stress in the target cell, triggering disorganization of the plasma membrane and cytoplasm and consequent cell death.

9.4. Cytotoxic and Apoptotic Effects of L-Amino Acid Oxidases. The mechanisms of cytotoxicity induced by LAAOs involve two processes: necrosis and apoptosis. Necrosis is related to the direct action of the enzyme or its catabolic products on the plasma membrane of the cell, promoting its degeneration [29, $36,123]$. In contrast, apoptosis is initiated through various pathways; one of them is the generation of reactive oxygen species and free radicals [124]. One common pathway of cell death involves the products of tumor suppressor genes, including p53, which induce apoptosis. Protein p53 participates in growth inhibition and DNA repair or apoptosis after DNA damage induced by cytotoxic agents [125]. Due to the central role of p53 in many human cancers, including gliomas, its regulation and expression might be a potential target in glial cell cancer therapy [126].

The induction of apoptosis in tumor cells is one of the most important mechanisms of anticancer agents. Apoptotic events coincide with morphological, biochemical, and molecular alterations that lead to cell death. The most frequent morphological alterations include chromatin condensation, disintegration of the nucleolus, and a reduction in cell volume. Biochemical alterations culminate in the production of oxidant enzymes, and molecular changes are associated with the fragmentation of DNA, as shown in Table 5.

According to Ponnudurai et al. [53], this biological effect may result from a secondary action of hydrogen peroxide produced during the oxidation reaction of the substrate. This theory is supported by the finding that the addition of catalase or GSH (glutathione) to LAAOs coincides with the loss of activity of these enzymes. Increasing evidence supporting this hypothesis includes the finding that hydrogen peroxide is a mediator of apoptosis that directly acts on oxidative cell metabolism [4]. 
TABLE 5: Cytotoxic and apoptotic effects of L-amino acid oxidases isolated from snake venom.

\begin{tabular}{|c|c|c|c|c|}
\hline Venom & Toxin & Cell line (DNA) & Concentration and treatment time & Reference \\
\hline Lachesis muta & LmLAAO & LL-24, AGS, MCF-7, and HUTU & $1.17-75 \mu \mathrm{g} / \mathrm{mL}$ for $24 \mathrm{~h}$ & [15] \\
\hline Bothrops leucurus & Bl-LAAO & MKN-45 and RKO & $0.1-20 \mu \mathrm{g} / \mathrm{mL}$ for $24 \mathrm{~h}$ & [17] \\
\hline Bungarus fasciatus & BF-LAAO & A549 & $0.03-3.0 \mu \mathrm{g} / \mathrm{mL}$ for $12 \mathrm{~h}$ & {$[55]$} \\
\hline Bothrops atrox & LAAO & PC12, B16F10, HL-60, and Jurkat & $5-50 \mu \mathrm{g} / \mathrm{mL}$ for $4 \mathrm{~h}$ & [45] \\
\hline Bothrops moojeni & BmooLAAO-I & HL-60 & $8-16 \mu \mathrm{g} / \mathrm{mL}$ for $12 \mathrm{~h}$ & {$[66]$} \\
\hline Agkistrodon acutus & ACTX-8 & $\mathrm{HeLa}$ & $20 \mu \mathrm{g} / \mathrm{mL}$ for $12-48 \mathrm{~h}$ & [29] \\
\hline Bothrops pirajai & BpirLAAO-I & Fago M13mp18 & $1-20 \mu \mathrm{g} / \mathrm{mL}$ for $24 \mathrm{~h}$ & {$[32]$} \\
\hline Vipera berus berus & $V$. berus berus LAAO & HeLa and K562 & $2.5-10 \mu \mathrm{g} / \mathrm{mL}$ for $7-24 \mathrm{~h}$ & [33] \\
\hline Trimeresurus flavoviridis & OHAP-1 & RBR17T and C6 & 2.5 and $5 \mu \mathrm{g} / \mathrm{mL}$ for $24 \mathrm{~h}$ & {$[48]$} \\
\hline Eristicophis macmahoni & LNV-LAO & MM6 & $25-100 \mu \mathrm{g} / \mathrm{mL}$ for $18 \mathrm{~h}$ & [83] \\
\hline Agkistrodon contortrix laticinctus & ACL LAO & HL-60 & $2.5-100 \mu \mathrm{g} / \mathrm{mL}$ for $16 \mathrm{~h}$ & [75] \\
\hline
\end{tabular}

Mosmann [127] observed that hydrogen peroxide induces the upregulation of Fas in human endothelial cells and that the activation of tyrosine kinase might be involved in the hydrogen peroxide-induced expression of Fas. Fas is a type I membrane protein belonging to the tumor necrosis factor and nerve growth factor receptor family and mediates a death signal. Thus, Fas-mediated apoptosis in human endothelial cells may contribute to the mechanism of hydrogen peroxideinduced endothelial cell injury.

Several of the LAAOs isolated have been considered cytotoxic, including APIT to Jurkat T cells [34], Vipera berus berus LAAO to HeLa and K562 cells [33], BpirLAAOI to S180 cells and macrophages [32], ABU-LAO to human monocytes and T cells [29], BmooLAAO-I to Ehrlich ascites tumor cells [66], BatroxLAAO to HL-60, Jurkat, B16F10, and PC12 cells [25], ACTX-8 to HeLa cells [29], BjarLAAO-I to Ehrlich ascites tumour [27], BF-LAAO to A549 cells [55], BpLAAO to SKBR3 breast carcinoma and Jurkat leukemia cells [24], BmarLAAO to macrophages [20], Bl-LAAO to LL24, RKO, HUTU, and MKN-45 cells [17], and LmLAAO to AGS cells-gastric adenocarcinoma and MCF-7 cells-breast adenocarcinoma [15].

DiPietrantonio et al. [128] detected an increased activity of caspase 3 in HL-60 cells exposed to hydrogen peroxide. Caspases are proteases of the cysteine family, which are common signaling molecules of apoptosis. Zhang et al. [129] demonstrated that TSV-LAO isolated from T. stejnegeri venom presents cytotoxicity in a human leukemia $\mathrm{T}$ cell line (C8166) by inducing chromatin condensation and nuclear morphological changes, which are typical phenomena of apoptosis.

Parallel to the treatment of svLAAOs cells infected with parasites, some authors do a first screening with different concentrations of the toxin on normal cells of the same lineage. The dose range that results in cell viability analyzed by MTT above $80 \%$ was adopted as criteria for further experiments. Under these conditions, the cells remain viable, but when they are infected with parasites and treated with different doses of the toxin in the range of previously found good viability, the intracellular multiplication of the parasite is inhibited [32].

\section{Pharmacological Applications of L-Amino Acid Oxidases}

According to Kitani et al. [130], SV-LAAOs have a large potential as cytotoxic drugs, based on cell viability obtained by MTT, according to the protocol described by Mosmann [127]. Previously published data have demonstrated cytotoxic activity to be an important characteristic of these enzymes, which started to receive attention for the development of new antimicrobial agents.

Sun et al. [19] demonstrated a protective effect of rat milk LAAOs on mammary glands. This effect is due to a probable antiseptic action of the enzyme when incorporated into milk. Inflammation and infections in the mammary glands are reduced by the presence of the antimicrobial agent, when continually secreted with milk.

According to Nuutinen and Timonen [6], the basidiomycetes Laccaria bicolor and Hebeloma spp., which live in symbiosis with tree roots of temperate and boreal forests, express the LAAO enzyme, whose function is to oxidize classical amino acids, generating nitrogen that undergoes mineralization to ammonia $\left(\mathrm{NH}^{4+}\right)$. Later, the nitrogen from this ammonia is utilized in the construction of amino acids by the host plant, besides ensuring the recycling of nitrogen derived from amino acids.

Achacin, an LAAO secreted in the mucus of the giant African snail (Achatina fulica), seems to protect this snail against aggressors, with the mucus forming a protective barrier against bacteria and fungi. Another LAAO, called SSAP, which is synthesized by the skin of the rockfish (Sebastes schlegeli) in the form of mucus, also exerts protective effects similar to those promoted by achacin $[128,130]$. This antimicrobial activity is probably related to the mechanism of action of the protein, which exerts a bactericidal effect by producing hydrogen peroxide and can be used as a natural repellent.

There are few leishmanicidal agents for the current leishmaniasis clinical therapy; in addition, visceral leishmaniasis may affect the liver and spleen and can become potentially lethal. Again, hydrogen peroxide was found to play a key role in the cytotoxic effect of the enzyme. However, partial 
retention of enzymatic activity after the addition of catalase showed the existence of other unknown mechanisms involved in the leishmanicidal and bactericidal effects of LAAO.

There are few effective drugs for the treatment of leishmaniasis, and in the visceral form this disease can affect the liver and spleen and can become potentially lethal; thus, LAAOs could be used as a potentiator of leishmanicidal action. However, its role as a toxin prevents everyday use, due to its nonspecific action. One way to use these toxins as possible therapeutic drugs is to alleviate them without losing the potential toxic effects, permitting their use in therapies or as models for the development of new drugs.

In 1997, the Korean group of Ahn et al. [108] published a study on the Ophiophagus hannah LAAO in which its cytotoxicity to tumors cells was evaluated using radioactively labeled thymidine uptake assays. Cytotoxicity was observed in stomach cancer, murine melanoma (B16F10), fibrosarcoma, colorectal cancer, and Chinese hamster ovary cell lines. Markland [131] suggested that this enzyme probably prevents the adhesion of tumor cells and metastases in the host by inhibiting platelet aggregation, in addition to promoting the attack of natural phagocytic cells of the immune system.

Another activity of svLAAOs is their antifung effect. According to Costa Torres et al. [20], a toxin called BmarLAAO isolated from the snake venom of Bothrops marajoensis is able to inhibit the growth of Candida albicans. Recently Cheng et al. [132] published a study showing that LAAOs induce apoptosis by DNA fragmentation of Botrytis cinerea.

\section{Concluding Remarks}

SvLAAOs, potentially toxic proteins, are present in different genera and families of snakes and are responsible for several biological activities. They catalyze a redox reaction of different groups of amino acids, generating hydrogen peroxide as a catabolic product. This reactive oxygen species so far seems to be the molecule responsible for the pharmacological effects of this class of enzymes.

Different LAAOs have been found to be valuable molecules with possible future applications to the treatment of many diseases and as models for the development of antiviral, antitumor, antiparasitic, and antimicrobial drugs. However, the development of therapeutic agents based on the structure of widely characterized molecules previously isolated from snake venoms is gaining popularity in the search for future drugs.

\section{Conflict of Interests}

The authors declare that there is no conflict of interests.

\section{Acknowledgments}

The authors are grateful to the Ministry of Science and Technology (MCT), Conselho Nacional de Desenvolvimento Científico e Tecnológico (CNPq), Financiadora de Estudos e
Projetos (FINEP), Fundação de Tecnologia do Acre (FUNTAC/FDCT), Coordenação de Aperfeiçoamento de Nível Superior (CAPES) Projeto NanoBiotec, Rede de Biodiversidade e Biotecnologia da Amazônia Legal (BIONORTE/ $\mathrm{CNPq} / \mathrm{MCT}$ ), Instituto Nacional para Pesquisa Translacional em Saúde e Ambiente na Região Amazônica (INCTINPeTAm/CNPq/MCT) e Instituto Nacional para Pesquisa em Toxinas (INCT-Tox), and the Secretary of Development of Rondonia State (SEPLAN/PRONEX/CNPq) for financial support.

\section{References}

[1] K. V. Kardong, "The evolution of the venom apparatus in snakes from Colubrids and Elapids," Memórias do Instituto Butantan, vol. 46, pp. 105-118, 1982.

[2] C. Gans, "Reptilian venom: some evolutionary considerations," in Biology of the Reptilia, C. Gans and K. A. Gans, Eds., vol. 8, pp. 1-42, Academic Press, London, UK, 1978.

[3] O. H. P. Ramos and H. S. Selistre-De-Araujo, "Snake venom metalloproteases-structure and function of catalytic and disintegrin domains," Comparative Biochemistry and Physiology C, vol. 142, no. 3-4, pp. 328-346, 2006.

[4] X.-Y. Du and K. J. Clemetson, "Snake venom L-amino acid oxidases," Toxicon, vol. 40, no. 6, pp. 659-665, 2002.

[5] T. Nishizawa, C. C. Aldrich, and D. H. Sherman, "Molecular analysis of the rebeccamycin L-amino acid oxidase from Lechevalieria aerocolonigenes ATCC 39243," Journal of Bacteriology, vol. 187, no. 6, pp. 2084-2092, 2005.

[6] J. T. Nuutinen and S. Timonen, "Identification of nitrogen mineralization enzymes, l-amino acid oxidases, from the ectomycorrhizal fungi Hebeloma spp. and Laccaria bicolor," Mycological Research, vol. 112, no. 12, pp. 1453-1464, 2008.

[7] H. A. Krebs, The Enzymes, vol. 217, Delmar Publishers, New York, NY, USA, 1st edition, 1933.

[8] M. Blanchard, D. Green, V. Nocito et al., "L-Amino acid oxidase of animal tissue," The Journal of Biological Chemistry, vol. 155, pp. 421-440, 1944.

[9] A. Zeller and A. Maritiz, "Uber eine neue L-aminosaure Oxidase," Helvetica Chimica Acta, vol. 27, pp. 1888-1902, 1944.

[10] S. Iwanaga and T. Suzuki, "Enzymes in snake venoms," in Handbook of Experimental Pharmacology. (Snake Venoms), C. Y. Lee, Ed., vol. 52, pp. 75-84, Springer, Berlin, Germany, 1979.

[11] E. K. Johnson, K. V. Kardong, and C. L. Ownby, "Observations on white and yellow venoms from an individual southern Pacific rattlesnake (Crotalus viridis helleri)," Toxicon, vol. 25, no. 11, pp. 1169-1180, 1987.

[12] L. J. Vargas, J. C. Quintana, J. A. Pereañez et al., "Cloning and characterization of an antibacterial L-amino acid oxidase from Crotalus durissus cumanensis venom," Toxicon, vol. 64, pp. 1-11, 2013.

[13] T. Ehara, S. Kitajima, N. Kanzawa, T. Tamiya, and T. Tsuchiya, "Antimicrobial action of achacin is mediated by L-amino acid oxidase activity," The FEBS Letters, vol. 531, no. 3, pp. 509-512, 2002.

[14] Y. Jin, W.-H. Lee, L. Zeng, and Y. Zhang, "Molecular characterization of l-amino acid oxidase from king cobra venom," Toxicon, vol. 50, no. 4, pp. 479-489, 2007.

[15] C. Bregge-Silva, M. C. Nonato, S. Albuquerque et al., "Isolation and biochemical, functional and structural characterization of 
a novel L-amino acid oxidase from Lachesis muta snake venom," Toxicon, vol. 60, pp. 1263-1276, 2012.

[16] H.-S. Chen, Y.-M. Wang, W.-T. Huang, K.-F. Huang, and I.H. Tsai, "Cloning, characterization and mutagenesis of Russell's viper venom 1-amino acid oxidase: insights into its catalytic mechanism," Biochimie, vol. 94, no. 2, pp. 335-344, 2012.

[17] G. B. Naumann, L. F. Silva, L. Silva et al., "Cytotoxicity and inhibition of platelet aggregation caused by an l-amino acid oxidase from Bothrops leucurus venom," Biochimica et Biophysica Acta, vol. 1810, no. 7, pp. 683-694, 2011.

[18] S. Kunalan, J. Vejayan, P. Navaratnam et al., "Purification and determination of antibacterial constituent, L-amino acid oxidase from Calloselasma rhodostoma and Ophiophagus Hannah," Abstracts Toxins/Toxicon, vol. 60, pp. 95-248, 2012.

[19] M.-Z. Sun, C. Guo, Y. Tian, D. Chen, F. T. Greenaway, and S. Liu, "Biochemical, functional and structural characterization of Akbu-LAAO: a novel snake venom l-amino acid oxidase from Agkistrodon blomhoffii ussurensis," Biochimie, vol. 92, no. 4, pp. 343-349, 2010.

[20] A. F. Costa Torres, R. T. Dantas, M. H. Toyama et al., "Antibacterial and antiparasitic effects of Bothrops marajoensis venom and its fractions: phospholipase $\mathrm{A}_{2}$ and l-amino acid oxidase," Toxicon, vol. 55, no. 4, pp. 795-804, 2010.

[21] S. S. More, K. M. Kiran, S. M. Veena, and J. R. Gadag, "Purification of an 1-amino acid oxidase from Bungarus caeruleus (Indian krait) venom," Journal of Venomous Animals and Toxins Including Tropical Diseases, vol. 16, no. 1, pp. 60-75, 2010.

[22] I. M. B. Francischetti, V. My-Pham, J. Harrison, M. K. Garfield, and J. M. C. Ribeiro, "Bitis gabonica (Gaboon viper) snake venom gland: toward a catalog for the full-length transcripts (cDNA) and proteins," Gene, vol. 337, pp. 55-69, 2004.

[23] P. Ciscotto, R. A. Machado de Avila, E. A. F. Coelho et al., "Antigenic, microbicidal and antiparasitic properties of an 1amino acid oxidase isolated from Bothrops jararaca snake venom," Toxicon, vol. 53, no. 3, pp. 330-341, 2009.

[24] R. S. Rodrigues, J. F. da Silva, J. Boldrini França et al., "Structural and functional properties of Bp-LAAO, a new l-amino acid oxidase isolated from Bothrops pauloensis snake venom," Biochimie, vol. 91, no. 4, pp. 490-501, 2009.

[25] R. M. Alves, G. A. Antonucci, H. H. Paiva et al., "Evidence of caspase-mediated apoptosis induced by l-amino acid oxidase isolated from Bothrops atrox snake venom," Comparative Biochemistry and Physiology, vol. 151, no. 4, pp. 542-550, 2008.

[26] M. D. M. Braga, A. M. C. Martins, D. N. Amora et al., "Purification and biological effects of 1 -amino acid oxidase isolated from Bothrops insularis venom," Toxicon, vol. 51, no. 2, pp. 199-207, 2008.

[27] C. D. Sant'Ana, D. L. Menaldo, T. R. Costa et al., "Antiviral and antiparasite properties of an 1-amino acid oxidase from the Snake Bothrops jararaca: cloning and identification of a complete cDNA sequence," Biochemical Pharmacology, vol. 76, no. 2, pp. 279-288, 2008.

[28] M. Samel, K. Tõnismägi, G. Rönnholm et al., "l-Amino acid oxidase from Naja naja oxiana venom," Comparative Biochemistry and Physiology B, vol. 149, no. 4, pp. 572-580, 2008.

[29] L. Zhang and L.-J. Wei, "ACTX-8, a cytotoxic l-amino acid oxidase isolated from Agkistrodon acutus snake venom, induces apoptosis in Hela cervical cancer cells," Life Sciences, vol. 80, no. 13, pp. 1189-1197, 2007.

[30] K. Tõnismägi, M. Samel, K. Trummal et al., "l-Amino acid oxidase from Vipera lebetina venom: isolation, characterization, effects on platelets and bacteria," Toxicon, vol. 48, no. 2, pp. 227237, 2006.

[31] M. H. Toyama, D. D. O. Toyama, L. F. D. Passero et al., "Isolation of a new L-amino acid oxidase from Crotalus durissus cascavella venom," Toxicon, vol. 47, no. 1, pp. 47-57, 2006.

[32] L. F. M. Izidoro, M. C. Ribeiro, G. R. L. Souza et al., "Biochemical and functional characterization of an l-amino acid oxidase isolated from Bothrops pirajai snake venom," Bioorganic and Medicinal Chemistry, vol. 14, no. 20, pp. 7034-7043, 2006.

[33] M. Samel, H. Vija, G. Rönnholm, J. Siigur, N. Kalkkinen, and E. Siigur, "Isolation and characterization of an apoptotic and platelet aggregation inhibiting l-amino acid oxidase from Vipera berus berus (common viper) venom," Biochimica et Biophysica Acta, vol. 1764, no. 4, pp. 707-714, 2006.

[34] D. Butzke, R. Hurwitz, B. Thiede, S. Goedert, and T. Rudel, "Cloning and biochemical characterization of APIT, a new Lamino acid oxidase from Aplysia punctata," Toxicon, vol. 46, no. 5, pp. 479-489, 2005.

[35] R. G. Stábeli, S. Marcussi, G. B. Carlos et al., "Platelet aggregation and antibacterial effects of an L-amino acid oxidase purified from Bothrops alternatus snake venom," Bioorganic and Medicinal Chemistry, vol. 12, no. 11, pp. 2881-2886, 2004.

[36] S. R. Ande, H. Fussi, H. Knauer et al., "Induction of apoptosis in yeast by L-amino acid oxidase from the Malayan pit viper Calloselasma rhodostoma," Yeast, vol. 25, no. 5, pp. 349-357, 2008.

[37] P. Macheroux, O. Seth, C. Bollschweiler et al., "L-amino-acid oxidase from the Malayan pit viper Calloselasma rhodostoma: comparative sequence analysis and charaterization of active and inactive forms of the enzyme," European Journal of Biochemistry, vol. 268, no. 6, pp. 1679-1686, 2001.

[38] S. S. Chen, J. Hudspeth Walgate, and J. A. Duerre, "Oxidative deamination of sulfur amino acids by bacterial and snake venom 1-amino acid oxidase," Archives of Biochemistry and Biophysics, vol. 146, no. 1, pp. 54-63, 1971.

[39] T. Ubuka and K. Yao, "Oxidative deamination of L-cystine by Lamino acid oxidase from snake venom: formation of S-(2-oxo2carboxyethylthiol) cysteine and S-(carboxymethylthiol) cystein," Biochemical and Biophysical Research Communications, vol. 55, no. 4, pp. 1305-1310, 1973.

[40] E. A. Zeller, "Snake venom action: are enzymes involved in it?" Experientia, vol. 33, no. 2, pp. 143-150, 1977.

[41] T. Ubuka, Y. Ishimoto, and K. Kasahara, "Determination of 3-mercaptopyruvate-cysteine disulfide, a product of oxidative deamination of l-cystine by l-amino acid oxidase," Analytical Biochemistry, vol. 67, no. 1, pp. 66-73, 1975.

[42] H.-S. Gewitz, J. Piefke, K. Langowska, and B. Vennesland, "The formation of hydrogen cyanide from histidine in the presence of amino acid oxidase and peroxidase," Biochemistry and Biophisical, vol. 611, no. 1, pp. 11-26, 1980.

[43] L.-K. Sun, Y. Yoshii, A. Hyodo et al., "Apoptotic effect in the glioma cells induced by specific protein extracted from Okinawa Habu (Trimeresurus flavoviridis) venom in relation to oxidative stress," Toxicology in Vitro, vol. 17, no. 2, pp. 169-177, 2003.

[44] K. Kasai, T. Ishikawa, T. Komata et al., "Novel l-amino acid oxidase with antibacterial activity against methicillin-resistant Staphylococcus aureus isolated from epidermal mucus of the flounder Platichthys stellatus," The FEBS Journal, vol. 277, no. 2, pp. 453-465, 2010.

[45] R. M. Alves, G. A. Antonucci, H. H. Paiva et al., "Evidence of caspase-mediated apoptosis induced by l-amino acid oxidase 
isolated from Bothrops atrox snake venom," Comparative Biochemistry and Physiology, vol. 151, no. 4, pp. 542-550, 2008.

[46] X.-L. Wei, J.-F. Wei, T. Li et al., "Purification, characterization and potent lung lesion activity of an l-amino acid oxidase from Agkistrodon blomhoffii ussurensis snake venom," Toxicon, vol. 50, no. 8, pp. 1126-1139, 2007.

[47] S.-R. Zhong, Y. Jin, J.-B. Wu et al., "Purification and characterization of a new l-amino acid oxidase from Daboia russellii siamensis venom," Toxicon, vol. 54, no. 6, pp. 763-771, 2009.

[48] L.-K. Sun, Y. Yoshii, A. Hyodo et al., "Apoptotic effect in the glioma cells induced by specific protein extracted from Okinawa Habu (Trimeresurus flavoviridis) venom in relation to oxidative stress," Toxicology in Vitro, vol. 17, no. 2, pp. 169-177, 2003.

[49] Z. Findrik, B. Geueke, W. Hummel, and D. Vasić-Rački, "Modelling of L-DOPA enzymatic oxidation catalyzed by L-amino acid oxidases from Crotalus adamanteus and Rhodococcus opacus," Biochemical Engineering Journal, vol. 27, no. 3, pp. 275286, 2006.

[50] I. M. Moustafa, S. Foster, A. Y. Lyubimov, and A. Vrielink, "Crystal structure of LAAO from Calloselasma rhodostoma with an 1-phenylalanine substrate: insights into structure and mechanism," Journal of Molecular Biology, vol. 364, no. 5, pp. 991-1002, 2006.

[51] W. K. Paik and S. Kim, "pH-substrate relationship of l-amino acid oxidases from snake venom and rat kidney," Biochimica and Biophysica Acta, vol. 96, no. 1, pp. 66-74, 1965.

[52] M. Ueda, C.-C. Chang, and M. Ohno, "Purification and characteriaztion of L-amino acid oxidase from the venom of Trimeresurus mucrosquamatus (Taiwan habu snake)," Toxicon, vol. 26, no. 8, pp. 695-706, 1988.

[53] G. Ponnudurai, M. C. M. Chung, and N.-H. Tan, "Purification and properties of the L-amino acid oxidase from Malayan pit viper (Calloselasma rhodostoma) venom," Archives of Biochemistry and Biophysics, vol. 313, no. 2, pp. 373-378, 1994.

[54] Z. Findrik and D. Vasić-Rački, "Mathematical modelling of amino acid resolution catalyzed by l-amino acid oxidases from Crotalus adamanteus and Crotalus atrox," Process Biochemistry, vol. 43, no. 11, pp. 1186-1194, 2008.

[55] J.-F. Wei, H.-W. Yang, X.-L. Wei, L.-Y. Qiao, W.-Y. Wang, and S.H. He, "Purification, characterization and biological activities of the l-amino acid oxidase from Bungarus fasciatus snake venom," Toxicon, vol. 54, no. 3, pp. 262-271, 2009.

[56] N.-H. Tan and S. Swaminathan, "Purification and properties of the L-amino acid oxidase from monocellate cobra (Naja naja kaouthia) venom," International Journal of Biochemistry, vol. 24, no. 6, pp. 967-973, 1992.

[57] N. H. Tan and M. N. Saifuddin, "Isolation and characterization of an unusual form of L-amino acid oxidase from King cobra (Ophiophagus hannah) venom," Biochemistry International, vol. 19, no. 4, pp. 937-944, 1989.

[58] D. S. Page and R. L. Van Etten, "L-amino acid oxidase. II. Deuterium isotope effects and the actino mechanism for the reduction of L-amino acid oxidase by L-leucine," Biochemistry and Biophisical, vol. 227, no. 1, pp. 16-31, 1971.

[59] C. Solis, E. Escobar, A. Yarleque et al., "Purificación y caracterización de la L-aminoácido oxidasa del veneno de la serpiente Bothrops brazili 'Jergón shushupe,' Revista Peruana de Biologia, vol. 6, pp. 75-84, 1999.

[60] C. J. Coles, D. E. Edmondson, and T. P. Singer, "Reversible inactivation of L-amino acid oxidase. Properties of the three conformational forms," The Journal of Biological Chemistry, vol. 252, no. 22, pp. 8035-8039, 1977.

[61] S. P. Mackessy, "Fractionation of red diamond rattlesnake (Crotalus ruber ruber) venom: protease, phosphodiesterase, Lamino acid oxidase activities and effects of metal ions and inhibitors on protease activity," Toxicon, vol. 23, no. 2, pp. 337340, 1985.

[62] B. Mannervick, V. Boggaram, I. Carlberg et al., The Catalytic Mechanism of Mechanism of Glutathione Reductasa-Flavin and Flavoproteins, Scientific Societies Press, Tokyo, Japan, 1st edition, 1980.

[63] Y. Cisneros, Características bioquímicas de una proteína antibacteriana aislada del veneno de Lachesis Muta "Shushupe" [Tesis para optar al Titulo profesional de Biólogo], UNMSM, Lima, Peru, 1996.

[64] M. Bender and L. Brubacher, Catálisis y acción enzimática, Reverte, Barcelona, Spain, 1st edition, 1977.

[65] T. P. Singer and E. B. Kearney, "The L-amino acid oxidases of snake venoms. II Isolation and Characterization of homogeneous L-amino acid oxidase," Archives Biochemistry and Biophysics, vol. 29, no. 1, pp. 190-209, 1950.

[66] R. G. Stábeli, C. D. Sant’Ana, P. H. Ribeiro et al., "Cytotoxic Lamino acid oxidase from Bothrops moojeni: biochemical and functional characterization," International Journal of Biological Macromolecules, vol. 41, pp. 132-140, 2007.

[67] S. Soltysik, C. M. Byron, G. H. Einarsdottir, and M. T. Stankovich, "The effects of reversible freezing inactivation and inhibitor binding on redox properties of l-amino-acid oxidase," Biochimica et Biophysica Acta, vol. 911, no. 2, pp. 201-208, 1987.

[68] D. Wellner and A. Meister, "Crystalline L-amino acid oxidase of Crotalus adamanteus," The Journal of Biological Chemistry, vol. 235, pp. 2013-2018, 1960.

[69] J.-F. Wei, Q. Wei, Q.-M. Lu et al., "Purification, characterization and biological activity of an L-amino acid oxidase from Trimeresurus mucrosquamatus venom," Acta Biochimica et Biophysica Sinica, vol. 35, no. 3, pp. 219-224, 2003.

[70] Q.-M. Lu, Q. Wei, Y. Jin, J.-F. Wei, W.-Y. Wang, and Y.-L. Xiong, "L-amino acid oxidase from Trimeresurus jerdonii snake venom: purification, characterization, platelet aggregationinducing and antibacterial effects," Journal of Natural Toxins, vol. 11, no. 4, pp. 345-352, 2002.

[71] J. W. Liu, M. Q. Chai, X. Y. Du et al., "Purification and characterization of L-amino acid oxidase from Agkistrodon halys pallas venom," Sheng Wu Hua Xue Yu Sheng Wu Wu Li Xue Bao, vol. 34, pp. 305-310, 2002.

[72] H. Takatsuka, Y. Sakurai, A. Yoshioka et al., "Molecular characterization of L-amino acid oxidase from Agkistrodon halys blomhoffii with special reference to platelet aggregation," Biochimica et Biophysica Acta, vol. 1544, no. 1-2, pp. 267-277, 2001.

[73] E. O. Sánchez and A. Magalhães, "Purification and partial characterization of an L-amino acid oxidase from bushmaster snake (Surucucu Pico de Jaca) Lachesis muta muta venom," Brazilian Journal of Medical and Biological Research, vol. 24, no. 3, pp. 249-260, 1991.

[74] A. Geyer, T. B. Fitzpatrick, P. D. Pawelek et al., "Structure and characterization of the glycan moiety of L-amino-acid oxidase from the Malayan pit viper Calloselasma rhodostoma," European Journal of Biochemistry, vol. 268, no. 14, pp. 4044-4053, 2001.

[75] D. H. F. Souza, L. M. Eugenio, J. E. Fletcher et al., "Isolation and structural characterization of a cytotoxic L-amino acid 
oxidase from Agkistrodon contortrix laticinctus snake venom: preliminary crystallographic data," Archives of Biochemistry and Biophysics, vol. 368, no. 2, pp. 285-290, 1999.

[76] Y. Kitani, N. Kikuchi, G. Zhang et al., "Antibacterial action of L-amino acid oxidase from the skin mucus of rockfish Sebastes schlegelii," Comparative Biochemistry and Physiology B, vol. 149, no. 2, pp. 394-400, 2008.

[77] R. Iijima, J. Kisugi, and M. Yamazaki, "L-Amino acid oxidase activity of an antineoplastic factor of a marine mollusk and its relationship to cytotoxicity," Developmental and Comparative Immunology, vol. 27, no. 6-7, pp. 505-512, 2003.

[78] P. Ciscotto, R. A. Machado de Avila, E. A. F. Coelho et al., "Antigenic, microbicidal and antiparasitic properties of an lamino acid oxidase isolated from Bothrops jararaca snake venom," Toxicon, vol. 53, no. 3, pp. 330-341, 2009.

[79] O. H. Lowry, N. J. Rosebrrough, A. L. Farr, and R. J. Randall, "Protein measurement with the Folin phenol reagent," The Journal of Biological Chemistry, vol. 193, no. 1, pp. 265-275, 1951.

[80] G. Oshima and S. Iwanaga, "Occurrence of glycoproteins in various snake venoms," Toxicon, vol. 7, no. 3, pp. 235-238, 1969.

[81] A. De Kok and C. Veeger, "Studies on L-amino acid oxidase I. Effects and the competitive inhibitors," Biochimica and Biophysica Acta, vol. 33, p. 345, 1968.

[82] A. de Kok and A. B. Rawitch, "Studies on L-amino acid oxidase. II. Dissociation and characterization of its subunits," Biochemistry, vol. 8, no. 4, pp. 1405-1411, 1969.

[83] S. A. Ali, F. Hamid, A. Abbasi, Z. H. Zaidi, and D. Shehnaz, "Pharmacological effects of the leaf-nosed viper snake (Eristocophis macmahoni) venom and its HPLC fractions," Toxicon, vol. 37, no. 8, pp. 1095-1107, 1999.

[84] M. C. Dos Santos, L. C. L. Ferreira, W. D. Da Silva, and M. F. D. Furtado De, "Caracterización de las actividades biológicas de los venenos "amarillo" y "blanco" de Crotalus durissus ruruima comparados con el veneno de Crotalus durissus terrificus. Poder neutralizante de los antivenenos frente a los venenos de Crotalus durissus ruruima," Toxicon, vol. 31, no. 11, pp. 1459-1470, 1993.

[85] Y. Sakurai, H. Takatsuka, A. Yoshioka et al., "Inhibition of human platelet aggregation by L-amino acid oxidase purified from Naja naja kaouthia venom," Toxicon, vol. 39, no. 12, pp. 1827-1833, 2001.

[86] H. Zhang, M. Teng, L. Niu et al., "Purification, partial characterization, crystallization and structural determination of AHP-LAAO, a novel L-amino-acid oxidase with cell apoptosisinducing activity from Agkistrodon halys pallas venom," Acta Crystallographica D, vol. 60, no. 5, pp. 974-977, 2004.

[87] B. G. Stiles, F. W. Sexton, and S. A. Weinstein, "Antibacterial effects of different snake venoms: purification and characterization of antibacterial proteins from Pseudechis australis (Australian king brown or mulga snake) venom," Toxicon, vol. 29, no. 9, pp. 1129-1141, 1991.

[88] B. G. Fry, W. Wüster, S. F. R. Ramjan, T. Jackson, P. Martelli, and R. M. Kini, "Analysis of Colubroidea snake venoms by liquid chromatography with mass spectrometry: evolutionary and toxinological implications," Rapid Communications in Mass Spectrometry, vol. 17, no. 18, pp. 2047-2062, 2003.

[89] R. D. G. Theakston, D. A. Warrell, and E. Griffiths, "Report of a WHO workshop on the standardization and control of antivenoms," Toxicon, vol. 41, no. 5, pp. 541-557, 2003.

[90] N.-H. Tan, K.-K. Lim, and M. I. N. Jaafar, "An investigation into the antigenic cross-reactivity of Ophiophagus hannah (king cobra) venom neurotoxin, phospholipase A2, hemorrhagin and
L-amino acid oxidase using enzyme-linked immunosorbent assay," Toxicon, vol. 31, no. 7, pp. 865-872, 1993.

[91] R. A. Harrison, W. Wüster, and R. D. G. Theakston, "The conserved structure of snake venom toxins confers extensive immunological cross-reactivity to toxin-specific antibody," Toxicon, vol. 41, no. 4, pp. 441-449, 2003.

[92] R. G. Stábeli, L. M. Pimenta Magalhães, H. S. Selistre-DeAraujo, and E. B. Oliveira, "Antibodies to a fragment of the Bothrops moojeni L-amino acid oxidase cross-react with snake venom components unrelated to the parent protein," Toxicon, vol. 46, no. 3, pp. 308-317, 2005.

[93] S. Torii, M. Naito, and T. Tsuruo, "Apoxin I, a novel apoptosisinducing factor with L-amino acid oxidase activity purified from western diamondback rattlesnake venom," Journal of Biological Chemistry, vol. 272, no. 14, pp. 9539-9542, 1997.

[94] A. A. Raibekas and V. Massey, "Primary structure of the snake venom L-amino acid oxidase shows high homology with the mouse B cell interleukin 4-induced Figl protein," Biochemical and Biophysical Research Communications, vol. 248, no. 3, pp. 476-478, 1998.

[95] S. C. França, S. Kashima, P. G. Roberto et al., "Molecular approaches for structural characterization of Bothrops l-amino acid oxidases with antiprotozoal activity: cDNA cloning, comparative sequence analysis, and molecular modeling," Biochemical and Biophysical Research Communications, vol. 355, no. 2, pp. 302-306, 2007.

[96] Phylogenetic analyses, http://www.Phylogeny.fr/.

[97] R. C. Edgar, "MUSCLE: multiple sequence alignment with high accuracy and high throughput," Nucleic Acids Research, vol. 32, no. 5, pp. 1792-1797, 2004.

[98] J. Castresana, "Selection of conserved blocks from multiple alignments for their use in phylogenetic analysis," Molecular Biology and Evolution, vol. 17, no. 4, pp. 540-552, 2000.

[99] S. Guindon and O. Gascuel, "A simple, fast, and accurate algorithm to estimate large phylogenies by maximum likelihood," Systematic Biology, vol. 52, no. 5, pp. 696-704, 2003.

[100] M. Anisimova and O. Gascuel, "Approximate likelihood-ratio test for branches: a fast, accurate, and powerful alternative," Systematic Biology, vol. 55, no. 4, pp. 539-552, 2006.

[101] J. D. Thompson, D. G. Higgins, and T. J. Gibson, "CLUSTAL $\mathrm{W}$ : improving the sensitivity of progressive multiple sequence alignment through sequence weighting, position-specific gap penalties and weight matrix choice," Nucleic Acids Research, vol. 22, no. 22, pp. 4673-4680, 1994.

[102] P. D. Pawelek, J. Cheah, R. Coulombe, P. Macheroux, S. Ghisla, and A. Vrielink, "The structure of L-amino acid oxidase reveals the substrate trajectory into an enantiomerically conserved active site," The EMBO Journal, vol. 19, no. 16, pp. 4204-4215, 2000.

[103] S. A. Ali, S. Stoeva, A. Abbasi et al., "Isolation, structural, and functional characterization of an apoptosis-inducing L-amino acid oxidase from leaf-nosed viper (Eristocophis macmahoni) snake venom," Archives of Biochemistry and Biophysics, vol. 384, no. 2, pp. 216-226, 2000.

[104] N. Guex and M. C. Peitsch, "SWISS-MODEL and the SwissPdbViewer: an environment for comparative protein modeling," Electrophoresis, vol. 18, no. 15, pp. 2714-2723, 1997.

[105] A. Bdolah, "Comparison of venoms from two subspecies of the false horned viper (Pseudocerastes persicus)," Toxicon, vol. 24, no. 7, pp. 726-729, 1986. 
[106] J. Bradley, B. J. Berger, and A. R. Bhatti, "Snake venom components and their cross-reactivity: a review," Biochemistry and Cell Biology, vol. 67, no. 9, pp. 597-601, 1989.

[107] N.-H. Tan and G. Ponnudurai, "A comparative study of the biological properties of some sea snake venoms," Comparative Biochemistry and Physiology B, vol. 99, no. 2, pp. 351-354, 1991.

[108] M. Y. Ahn, B. M. Lee, and Y. S. Kim, "Characterization and cytotoxicity of L-amino acid oxidase from the venom of king cobra (Ophiophagus hannah)," International Journal of Biochemistry and Cell Biology, vol. 29, no. 6, pp. 911-919, 1997.

[109] I. Nathan, A. Dvilansky, and T. Yirmiyahu, "Impairment of platelet aggregation by Echis colorato venom mediated by Lamino acid oxidase or $\mathrm{H}_{2} \mathrm{O}_{2}$, "Thrombosis and Haemostasis, vol. 48, no. 3, pp. 277-282, 1982.

[110] Z.-Y. Li, T.-F. Yu, and E. C.-Y. Lian, "Purification and characterization of L-amino acid oxidase from king cobra (Ophiophagus hannah) venom and its effects on human platelet aggregation," Toxicon, vol. 32, no. 11, pp. 1349-1358, 1994.

[111] J. Wang, Q. Huang, M. Teng, and L. Niu, Purification, Cloning and Characterization of the L-Amino Acid Oxidase in Snake Trimeresurus Stejnegeri, School of Life Sciences, University of Science and Technology, 2003.

[112] Y. Sakurai, M. Shima, T. Matsumoto et al., "Anticoagulant activity of M-LAO, L-amino acid oxidase purified from Agkistrodon halys blomhoffii, through selective inhibition of factor IX," Biochimica et Biophysica Acta, vol. 1649, no. 1, pp. 51-57, 2003.

[113] R. Fernandez-Gomez, H. Zerrouk, F. Sebti, M. Loyens, A. Benslimane, and M. Ali Ouaissi, "Growth inhibition of Trypanosoma cruzi and Leishmania donovani infantum by different snake venoms: preliminary identification of proteins from Cerastes cerastes venom which interact with the parasites," Toxicon, vol. 32, no. 8, pp. 875-882, 1994.

[114] A. R. Gonçalves, M. J. Soares, W. De Souza, R. A. DaMatta, and E. W. Alves, "Ultrastructural alterations and growth inhibition of Trypanosoma cruzi and Leishmania major induced by Bothrops jararaca venom," Parasitology Research, vol. 88, no. 7, pp. 598-602, 2002.

[115] W. Peters and R. Killick-Kendrick, The Leishmaniasis in Biology and Medicine, Academic Press, New York, NY, USA, 1987.

[116] T. M. Buttke and P. A. Sandstrom, "Oxidative stress as a mediator of apoptosis," Immunology Today, vol. 15, no. 1, pp. 7-10, 1994.

[117] M. L. Pessatti, J. D. Fontana, M. F. D. Furtado et al., "Screening of Bothrops snake venoms for l-amino acid oxidase activity," Applied Biochemistry and Biotechnology, vol. 51-52, no. 1, pp. 197-210, 1995.

[118] H. W. Murray, "Susceptibility of Leishmania to oxygen intermediates and killing by normal macrophages," Journal of Experimental Medicine, vol. 153, no. 5, pp. 1302-1315, 1981.

[119] R. C. Skarnes, "L-amino-acid oxidase, a bactericidal system," Nature, vol. 225, no. 5237, pp. 1072-1073, 1970.

[120] M. L. Lee, N. H. Tan, S. Y. Fung, and S. D. Sekaran, "Antibacterial action of a heat-stable form of 1-amino acid oxidase isolated from king cobra (Ophiophagus hannah) venom," Comparative Biochemistry and Physiology C, vol. 153, no. 2, pp. 237-242, 2011.

[121] P. Marcotte and C. Walsh, "Vinylglycine and propargylglycine: complementary suicide substrates for L-amino acid oxidase and D-amino acid oxidase," Biochemistry, vol. 15, no. 14, pp. 30703076, 1976.
[122] A. G. Tempone, J. Andrade H.F., P. J. Spencer, C. O. Lourenço, J. R. Rogero, and N. Nascimento, "Bothrops moojeni venom kills Leishmania spp. with hydrogen peroxide generated by its L-amino acid oxidase," Biochemical and Biophysical Research Communications, vol. 280, no. 3, pp. 620-624, 2001.

[123] T. Suhara, K. Fukuo, T. Sugimoto et al., "Hydrogen peroxide induces up-regulation of Fas in human endothelial cells," Journal of Immunology, vol. 160, no. 8, pp. 4042-4047, 1998.

[124] M. M. De Vieira Santos, C. D. Sant’Ana, J. R. Giglio et al., "Antitumoural effect of an L-amino acid oxidase isolated from Bothrops jararaca snake venom," Basic and Clinical Pharmacology and Toxicology, vol. 102, no. 6, pp. 533-542, 2008.

[125] A. M. Dipietrantonio, T.-C. Hsieh, and J. M. Wu, "Activation of caspase 3 in HL-60 cells exposed to hydrogen peroxide," Biochemical and Biophysical Research Communications, vol. 255, no. 2, pp. 477-482, 1999.

[126] M. Y. Ahn, B. M. Lee, and Y. S. Kim, "Characterization and cytotoxicity of L-amino acid oxidase from the venom of king cobra (Ophiophagus hannah)," The International Journal of Biochemistry and Cell Biology, vol. 29, no. 6, pp. 911-919, 1997.

[127] T. Mosmann, "Rapid colorimetric assay for cellular growth and survival: application to proliferation and cytotoxicity assays," Journal of Immunological Methods, vol. 65, no. 1-2, pp. 55-63, 1983.

[128] A. M. DiPietrantonio, T. Hsieh, and J. M. Wu, "Activation of caspase 3 in HL-60 cells exposed to hydrogen peroxide," Biochemical and Biophysical Research Communications, vol. 255, no. 2, pp. 477-482, 1999.

[129] Y. J. Zhang, J. H. Wang, W. H. Lee et al., "Molecular characterization of Trimeresurus stejnegeri venom L-amino acid oxidase with potential anti-HIV activity," Acta Crystallography, vol. 60, pp. 974-977, 2004.

[130] Y. Kitani, K. Toyooka, M. Endo et al., "Intra-tissue localization of an antibacterial L-amino acid oxidase in the rockfish Sebastes schlegeli," Developmental and Comparative Immunology, vol. 39, pp. 456-459, 2013.

[131] F. S. Markland, "Snake venoms and the hemostatic system," Toxicon, vol. 36, no. 12, pp. 1749-1800, 1998.

[132] C.-H. Cheng, C.-A. Yang, S.-Y. Liu, C.-T. Lo, and K.-C. Peng, "LAmino acid oxidase-induced apoptosis in filamentous Botrytis cinerea," Analytical Biochemistry, vol. 420, no. 1, pp. 93-95, 2012. 

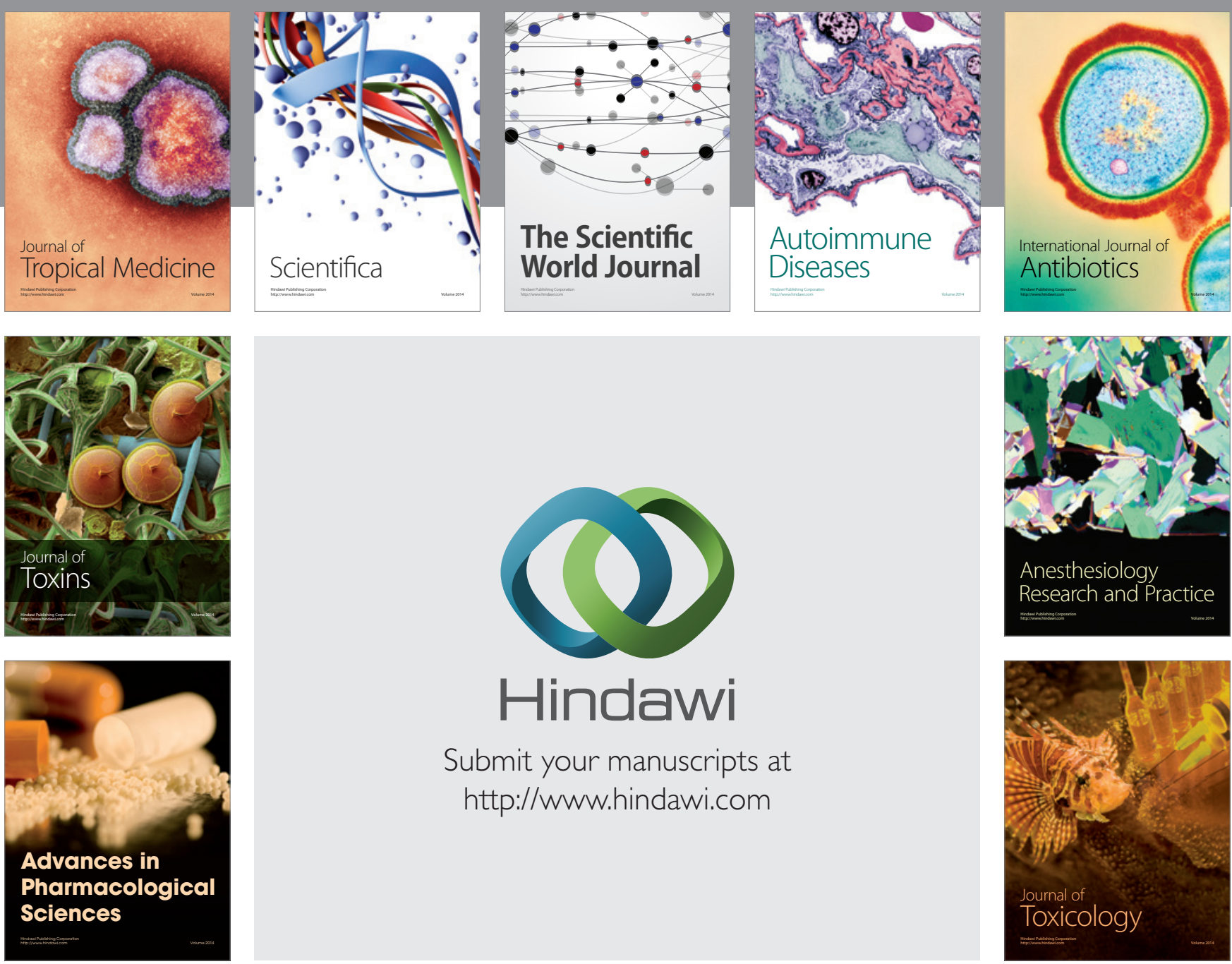

\section{Hindawi}

Submit your manuscripts at

http://www.hindawi.com
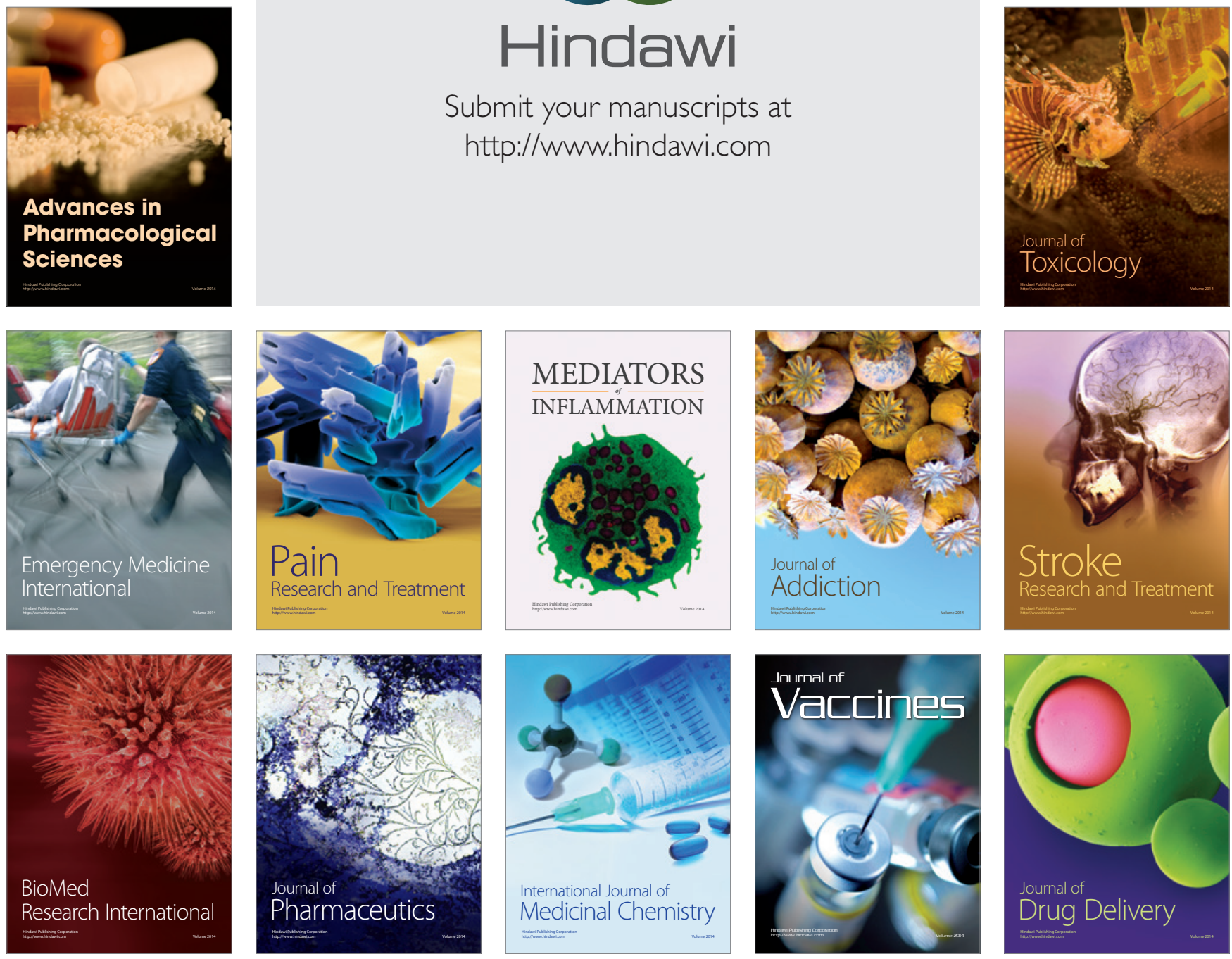